Research Article

\title{
pH Sensitivity Estimation in Potentiometric Metal Oxide pH Sensors Using the Principle of Invariance
}

\author{
Siddharth Ravichandran (D), ${ }^{1}$ Chockalingam Thiagarajan $\left(\mathrm{D},{ }^{1}\right.$ \\ and Ponnusamy Senthil Kumar $\mathbb{D}^{2}$ \\ ${ }^{1}$ Sreemagal Computers, 309 Phase 3, Golden Park Apartments, Kodichikkanahalli, Devarachikkanahalli Main Road,
Bangalore 560076, India
${ }^{2}$ Department of Chemical Engineering, Sri Sivasubramaniya Nadar College of Engineering, Chennai 603110, India
}

Correspondence should be addressed to Ponnusamy Senthil Kumar; senthilkumarp@ssn.edu.in

Received 25 January 2021; Revised 3 March 2021; Accepted 6 March 2021; Published 13 March 2021

Academic Editor: Vikranth Kumar Surasani

Copyright (C) 2021 Siddharth Ravichandran et al. This is an open access article distributed under the Creative Commons Attribution License, which permits unrestricted use, distribution, and reproduction in any medium, provided the original work is properly cited.

\begin{abstract}
A numerically solvable engineering model has been proposed that predicts the sensitivity of metal oxide- $\left(\mathrm{MO}_{\mathrm{X}^{-}}\right)$based potentiometric $\mathrm{pH}$ sensors. The proposed model takes into account the microstructure and crystalline structure of the $\mathrm{MO}_{X}$ material. The predicted $\mathrm{pH}$ sensitivities are consistent with experimental results with the difference below $6 \%$ across three $\mathrm{MO}_{X}\left(\mathrm{RuO}_{2}, \mathrm{TiO}_{2}\right.$, and $\mathrm{Ta}_{2} \mathrm{O}_{5}$ ) analysed. The model distinguishes the performance of different $\mathrm{MO}_{X}$ phases by the appropriate choice of surface hydroxyl site densities and dielectric constants, making it possible to estimate the performance of $\mathrm{MO}_{X}$ electrodes fabricated through different high-temperature and low-temperature annealing methods. It further addresses the problem, cited by theoreticians, of independently determining the $C_{1}$ inner Helmholtz capacitance parameter while applying the triple-layer model to $\mathrm{pH}$ sensors. This is done by varying the $C_{1}$ capacitance parameter until an invariant $\mathrm{pH}$ sensitivity across different electrolyte ionic strengths is obtained. This invariance point identifies the $C_{1}$ capacitance. The corresponding $\mathrm{pH}$ sensitivity is the characteristic sensitivity of $\mathrm{MO}_{X}$. The model has been applied across different types of metal oxides, namely, expensive platinum group oxides $\left(\mathrm{RuO}_{2}\right)$ and cheaper nonplatinum group $\mathrm{MO}_{X}\left(\mathrm{TiO}_{2}\right.$ and $\left.\mathrm{Ta}_{2} \mathrm{O}_{5}\right)$. High temperature annealed, $\mathrm{RuO}_{2}$ produced a high $\mathrm{pH}$ sensitivity of $59.1082 \mathrm{mV} / \mathrm{pH}$, while TiO 2 and $\mathrm{Ta}_{2} \mathrm{O}_{5}$ produced sub-Nernstian sensitivities of 30.0011 and $34.6144 \mathrm{mV} / \mathrm{pH}$, respectively. Low temperature annealed, $\mathrm{TiO}_{2}$ and $\mathrm{Ta}_{2} \mathrm{O}_{5}$ produced Nernstian sensitivities of 59.1050 and $59.1081 \mathrm{mV} / \mathrm{pH}$, respectively, illustrating the potential of using cheaper nonplatinum group $\mathrm{MO}_{x}$ as alternative sensor electrode materials. Separately, the usefulness of relatively less investigated, cheap, and readily available $\mathrm{MO}_{X}$, viz. $\mathrm{Al}_{2} \mathrm{O}_{3}$, as the electrode material was analysed. Low-temperature-annealed $\mathrm{Al}_{2} \mathrm{O}_{3}$ with a Nernstian sensitivity of $59.1050 \mathrm{mV} / \mathrm{pH}$ can be considered as a potential electrode material. The proposed engineering model can be used as a preliminary prediction mechanism for choosing potentially cheaper alternative sensor electrode materials.
\end{abstract}

\section{Introduction}

Metal oxide $\left(\mathrm{MO}_{\mathrm{X}}\right)$ sensors are of great interest in air and water quality detection systems, with gas sensors being a prime application area [1]. In recent times, development of new sensors and improving the efficiency of existing sensors have received the attention of researchers [2]. The use of $\mathrm{MO}_{X}$ enhances the selectivity and sensitivity of existing sensor devices and also allows for real-time sensing of multiple parameters concurrently [1]. This is especially relevant for $\mathrm{MO}_{X}$-based $\mathrm{pH}$ sensors which have been gaining popularity in application areas of daily importance such as food quality inspections [3] and in new-generation biomedical devices [4]. The use of $\mathrm{WO}_{3}$ nanoparticle-based conformable $\mathrm{pH}$ sensor in wearable biomedical devices [5] is one such example of active research taking place in this domain. Much of the development of electrochemical $\mathrm{MO}_{X}$-based $\mathrm{pH}$ sensors has focused on potentiometric $\mathrm{pH}$ sensors which involve a $\mathrm{MO}_{X}$-based sensitive electrode and a reference electrode [6]. Potentiometric $\mathrm{pH}$ sensors are based on the principle of measuring the potential difference between the reference electrode and the sensitive electrode 
which are immersed in an analyte solution of unknown $\mathrm{pH}$. The sensitivity of such a sensor is a significant performance parameter since a greater sensitivity would allow for the detection of small $\mathrm{pH}$ changes in the analyte solution. The sensitivity performance of a sensor is determined by the degree to which the sensitivity factor is close to the ideal Nernstian response, as predicted by the Nernst equation $\left(59.14 \mathrm{mV} / \mathrm{pH}\right.$ at $\left.25^{\circ} \mathrm{C}\right)$. A sensitivity factor close to this Nernstian value is thus desired.

The empirical determination of such sensitivity characteristics of $\mathrm{MO}_{X}$ through experimental methods has been a matter of great interest to many researchers [7-11]. A theoretical model to predict the $\mathrm{pH}$ sensitivity of the $\mathrm{MO}_{X}$ electrodes would be of a complementary value in optimizing the cost and time involved in experiment-based characterization. Furthermore, the sensitivity of a $\mathrm{MO}_{X}$-based $\mathrm{pH}$ sensor is found to be dependent not only on metal oxide used for the sensitive electrode but also on the fabrication methods which could influence the microstructure, porosity, surface homogeneity, and crystalline structure of the material as observed by Manjakkal et al. [6]. Thus, the need for a quantitative prediction model for sensitivity that involves both the electrode material and the fabrication method variations is abundantly clear. Furthermore, with current research works attempting to consider mixed metal oxides as possible cheaper alternatives as materials for the sensor electrodes [12-14], a theoretical model that predicts the performance of pure metal oxides is of great value in deriving such models for mixed metal oxides.

1.1. The Faradaic and Nonfaradaic Approaches. There exist two broad approaches, one capturing the faradaic and the other nonfaradaic reactions, in modelling the sensing mechanism of $\mathrm{MO}_{X} \mathrm{pH}$ sensors. Among the five plausible mechanisms proposed by Fog and Buck [15] in their paper, the mechanism that involves ion exchange with the oxide surface layer imbibes both faradaic and nonfaradaic approaches. Both approaches involve the use of the Nernst equation, which captures the transduction of the $\mathrm{pH}$ variation as a measurable potential difference variation across the sensor electrodes. Faradaic processes involve the transfer of charged particles (electrons or ions) across the electrode without charge being progressively stored in the electrode [16]. These processes typically involve redox reactions. On the contrary, nonfaradaic processes involve the transfer of only ions, without electron transfer, but with progressive storage of charge. This allows nonfaradaic processes to be viewed as capacitive processes [16].

It is pertinent to discuss the limitations of applying the faradaic approach to model potentiometric sensor behaviour. This approach predicts the sensitivity based only on the number of electrons transferred through the redox reactions between the electrode and the electrolyte. This is because the Nernst equation serves as a linkage between the electrode potential and the concentration of participants in the electrode process [17]. Furthermore, it is an equation that is based on ideal surface conditions. One-electron electrode reaction would always result in an ideal slope factor of $59.14 \mathrm{mV} / \mathrm{pH}$ as the sensitivity of the sensor [6].
However, in reality, it is possible to approach this ideal Nernstian response across different fabrication methods only for certain "active" transition oxides such as $\mathrm{RuO}_{2}$ and $\mathrm{IrO}_{2}$ [6]. On the contrary, sensitivity studies on sensor electrodes fabricated using other $\mathrm{MO}_{X}$ such as $\mathrm{TiO}_{2}, \mathrm{Ta}_{2} \mathrm{O}_{5}$, and $\mathrm{CeO}_{2}$, which involve the same one-electron electrode reactions, yield mixed results with some claiming high Nernstian sensitivities while the others sub-Nernstian sensitivities. The differences in the sensor fabrication methodology have been cited as a possible reason behind these observations [7, 18]. These variations however cannot be explained solely by considering faradaic processes.

Low-temperature annealing leads to large grain sizes that result in reduced leakage current due to a smaller number of grain boundaries [19]. On the contrary, high-temperature annealing leads to polycrystalline materials with smaller grain sizes and an increased leakage current due to increased number of grain boundaries [9]. The faradaic approach ignores this aspect of the material phase in polycrystalline materials as it assumes an ideal transfer of electrons across the electrolyte interface, resulting in an overestimation of the sensitivity of such electrodes. In contrast, a nonfaradaic approach, such as the site-binding theory, takes into account parameters such as the total number of surface hydroxyl groups per unit area, $N_{S}$, and the dielectric constant of the electrode material, $\varepsilon_{s}$, which allow for the distinction of different $\mathrm{MO}_{X}$ based on phase differences. The value of $N_{s}$ depends on the crystalline structure of the $\mathrm{MO}_{X}$ material [6].

Since the fabrication method or the annealing temperature of $\mathrm{MO}_{X}$ materials affects the phase transformation of the materials [20], any theoretical approach to determine $\mathrm{pH}$ sensitivity should take into account $N_{s}$ and $\varepsilon_{s}$ as input parameters. Furthermore, the faradaic approach ignores the ionic interactions between the hydroxyl groups present on the $\mathrm{MO}_{X}$ surface and the ions present in the electrolyte bulk. The actual amount of hydroxyl groups on the $\mathrm{MO}_{X}$ surface available for sensing hydrogen ions would thus be overestimated in this approach resulting in a prediction of greater than expected sensitivities.

Only the faradaic approach has thus far been suggested for potentiometric sensors as seen in Al-Hilli and Willander's work on $\mathrm{ZnO}$ nanorods [21], while the nonfaradaic approach (site-binding theory) has been suggested for ISFET sensors [22]. Kurzweill, in his work [23], mentioned that metal oxides, in general, can be viewed as mixed electronic and ionic conductors due to their oxygen defect stoichiometry. He claimed that modelling surface phenomena at ion exchanging surface sites is by itself sufficient to explain the mechanism of the $\mathrm{pH}$ response of metal oxides and that it is not necessary to include $\mathrm{pH}$-dependent redox transitions. However, the scope of that work was limited to discussing platinum group oxides or "active" transition oxides such as $\mathrm{RuO}_{2}$ in this context.

1.2. A New Perspective on Potentiometric Sensing. A new perspective on the complex mechanism of potentiometric $\mathrm{pH}$ sensors has been developed in this work to unify various observations and theories made by experimenters and 
theoreticians alike in this field. Our perspective considers two groups of metal oxides; the first group is made of active transition oxides and metal oxides fabricated through lowtemperature annealing methods, while the second group constitutes metal oxides fabricated through high-temperature annealing methods and nonstoichiometric $\mathrm{MO}_{X}$. The first group can be viewed as ideal $\mathrm{pH}$ sensor materials that produce sensitivities close to the predicted theoretical Nernstian sensitivity value. The potential difference developed when this group of metal oxides is in contact with the electrolyte solution can be modelled using a faradaic and a nonfaradaic voltage source connected in parallel, across the space charge and triplelayer capacitance represented as capacitors connected in series as seen in Figure 1.

The faradaic voltage source represents the potential difference developed across the sensitive $\mathrm{MO}_{X}$ electrode and reference electrode through Faradaic processes. These processes refer to the redox reactions that take place on the interface of the $\mathrm{MO}_{X}$ electrode surface and the electrolyte solution. The charge (electrons and ions) transfer that takes place in these reactions contributes to the voltage that is developed. Trasatti developed a mechanism that captures this process for $\mathrm{RuO}_{2}$ [24]. The following mechanism represents the general faradaic process:

$$
\mathrm{MO}_{x}(\mathrm{OH})_{y}+\delta \mathrm{H}^{+}+\delta \mathrm{e}^{-} \leftrightharpoons \mathrm{MO}_{x-\delta}(\mathrm{OH})_{y+\delta},
$$

where $\mathrm{MO}_{x}(\mathrm{OH})_{y}$ is a higher valency metal oxide, while $\mathrm{MO}_{x-\delta}(\mathrm{OH})_{y+\delta}$ is a lower valency metal oxide.

The other voltage source in the model refers to the potential difference developed through nonfaradaic processes occurring across $\mathrm{MO}_{X}$ and reference electrodes. These processes refer to the ion transfer that occurs during surface protonation/deprotonation reactions and surface complexation reactions. The protonation/deprotonation reactions occur between species such as $\mathrm{SOH}, \mathrm{SO}^{-}, \mathrm{SOH}_{2}^{+}$, and $\mathrm{H}^{+}$ions in the electrolyte solution according to the following equilibrium [25], where $S$ refers to a generic metal constituent of metal oxide in the study:

$$
\begin{aligned}
& \mathrm{SOH}+\mathrm{H}^{+} \leftrightharpoons \mathrm{SOH}_{2}^{+}, \\
& \mathrm{SOH} \leftrightharpoons \mathrm{SO}^{-}+\mathrm{H}^{+} .
\end{aligned}
$$

Surface complexation reactions occur between species such as $\mathrm{SO}^{-}$and $\mathrm{SOH}_{2}^{+}$and electrolyte ions that are present. The equilibrium can be expressed in the following with $\mathrm{K}^{+}$ and $\mathrm{Cl}^{-}$as the electrolyte ions as an example:

$$
\begin{aligned}
& \mathrm{SOH}_{2}^{+}+\mathrm{Cl}^{-} \leftrightharpoons \mathrm{SOH}_{2}^{+} \mathrm{Cl}^{-}, \\
& \mathrm{SO}^{-} \mathrm{K}^{+} \leftrightharpoons \mathrm{SO}^{-}+\mathrm{K}^{+} .
\end{aligned}
$$

The developed voltage across the sensitive $\mathrm{MO}_{X}$ electrode and the reference electrode drops across a series of capacitances in the $\mathrm{MO}_{X}$-electrolyte interface, represented as $C_{\mathrm{SC}}$ and $C_{\mathrm{SS}}$, and the electrolyte itself, represented as $C_{\mathrm{H}}$ and $C_{\mathrm{G}}[26,27]$.

$C_{\mathrm{SC}}$ refers to the capacitance developed across the space-charge layer of the $\mathrm{MO}_{X}$ electrode, while $C_{\mathrm{SS}}$ refers

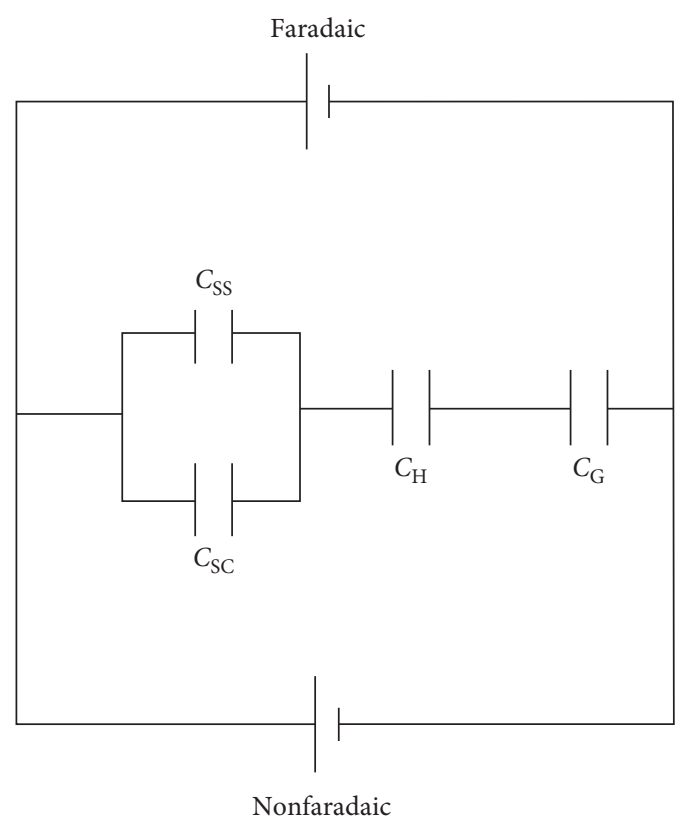

FIGURE 1: Schematic of the model that represents the potential difference across the electrolytic bulk for ideal $\mathrm{MO}_{x}$ electrodes.

to the surface-state capacitance. $C_{\mathrm{H}}$ refers to the Helmholtz layer capacitance, while $C_{\mathrm{G}}$ refers to the Gouy diffuse-layer capacitance.

The second group of metal oxides is more likely to produce sub-Nernstian sensitivities and thus could be termed as nonideal $\mathrm{MO}_{X}$ materials. This includes nonstoichiometric metal oxides since reduction in oxygen sites on the electrode surface caused by oxygen out-diffusion would result in reduced surface hydroxyl sites and thus reduced $\mathrm{pH}$ sensitivity [9]. The potential difference developed when this group of metal oxides is in contact with the electrolyte solution can be modelled as seen in Figure 2. In this model, the dominance of the nonfaradaic process (ion transfer) in causing the potential difference is captured by the single voltage source, which is across the space charge and triple-layer capacitance represented as capacitors connected in series.

\section{Proposed Engineering Model}

The new perspective discussed above for potentiometric $\mathrm{pH}$ sensing mechanisms paves the way for an engineering model to be suggested. The engineering model proposed in this work aims to provide a general mechanism to predict the $\mathrm{pH}$ response across different $\mathrm{MO}_{X}$ materials and their fabrication methods using the "triple-layer model" (TLM), as developed by Davis et al. [28], as the basis. When the electrode surface comes into contact with the electrolyte solution, the electric charge is induced on the electrode surface. This induced charge disrupts the ions present in the electrolyte, resulting in ions of opposite charge to be adsorbed towards the surface [29]. This layer is known as the Helmholtz layer.

The TLM captures the reactions that take place in the diffuse, inner, and outer Helmholtz layers. The TLM provides the sum of potential drops across the Helmholtz 


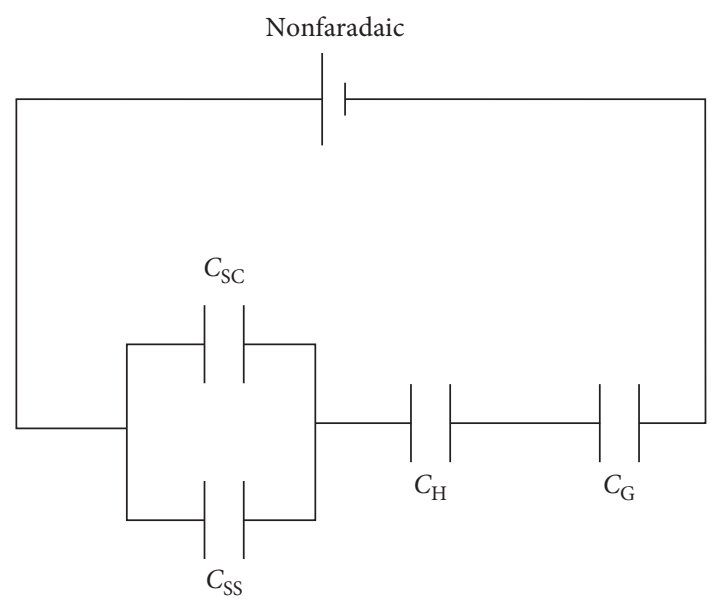

FIgURE 2: Schematic of the model that represents the potential difference across the electrolytic bulk for nonideal $\mathrm{MO}_{X}$ electrodes.

capacitance, $V_{\mathrm{H}}$, and the Gouy diffuse-layer capacitance, $V_{\mathrm{G}}$, for a certain $\mathrm{pH}$ value. Some of the model parameters required to apply the TLM were estimated using existing theoretical methods. In our engineering model, the total electrode potential for specific $\mathrm{pH}$ is expressed as a summation of the potentials $V_{\mathrm{H}}, V_{\mathrm{G}}$ and the potential drop across the space-charge layer capacitance, $V_{\mathrm{SC}}$. The contribution to the electrode potential by surface states $\left(V_{\mathrm{SS}}\right)$ is ignored in this model. This model alleviates the problem of independently determining the $C_{1}$ inner Helmholtz capacitance parameter required to apply the TLM for $\mathrm{pH}$ sensors cited by theoreticians. This has been done by varying the $C_{1}$ capacitance parameter value until invariant $\mathrm{pH}$ sensitivity across different ionic strengths is obtained. It also provides a means to obtain a close estimate of the actual $\mathrm{pH}$ sensitivity empirically determined through experiments through the electrolyte ionic strength invariant $\mathrm{pH}$ sensitivity.

The annealing temperature of the $\mathrm{MO}_{X}$ material to fabricate the electrode has a strong influence on the phase of $\mathrm{MO}_{X}$ on the sensing electrode [20]. The model distinguishes the performance of different metal oxide phases by choosing appropriate surface hydroxyl site densities and dielectric constants. The electrode potentials are calculated through the above method for a defined range of $\mathrm{pH}$ values for a specific $C_{1}$ capacitance. The calculated electrode potentials against $\mathrm{pH}$ are plotted, and a linear regression fit is used to model the dataset. The slope of the linear regression fit obtained is represented as the sensitivity of the $\mathrm{MO}_{X}$ electrode material for the chosen $C_{1}$ and electrolyte concentrations in this work. These slopes for various $C_{1}$ capacitances and electrolyte concentrations are used to predict the sensitivity of the $\mathrm{MO}_{X}$ material. This work analyses four different metal oxides, $\mathrm{RuO}_{2}, \mathrm{TiO}_{2}, \mathrm{Ta}_{2} \mathrm{O}_{5}$, and $\mathrm{Al}_{2} \mathrm{O}_{3}$, and their respective different phases determined by their fabrication method temperature.

There have been other previous attempts made to provide an estimate of $C_{1}$. One such work focuses on independently evaluating $C_{1}$ from the intrinsic properties of $\mathrm{MO}_{X}$ and the electrolyte solution [30]. The work proposes a theoretical model predicting $C_{1}$ for different metal oxide combinations through the use of Born solvation theory and the intrinsic properties of the $\mathrm{MO}_{X}$ materials such as their dielectric constant. However, this model requires the use of surface charge data from titration to obtain $C_{1}$ through experimental fits and does not provide a handle for electrolyte ionic strength variation. Since the TLM takes into account ionic strength as a parameter, a $C_{1}$ value predicted using this method would result in different $\mathrm{pH}$ sensitivities when applied in the model. This is to be expected as electrolyte concentrations are claimed to influence the mechanism of adsorption on electrode surfaces [31]. Thus, this method is of limited use in a potentiometric $\mathrm{pH}$ sensor context where an invariant $\mathrm{pH}$ sensitivity across ionic strengths is required to reflect the experimental observations.

Other studies have also been conducted in a similar vein such as the one by Hwang and Lenhart [32], which evaluated the dependence of $N_{s}$ on $C_{1}$ capacitance values for haematite. This work relies on surface titration data obtained from experiments. The results and analysis are thus specific to the haematite material. Such experimental data would otherwise be unavailable for generic $\mathrm{MO}_{X}$ to be input as parameters into the TLM, limiting the scope of the work to a specific material.

\section{Theory}

This engineering model would solely make use of the nonfaradaic approach to model the $\mathrm{pH}$ response mechanism of potentiometric $\mathrm{pH}$ sensors. The nonfaradaic processes have been demonstrated to account for the potential difference across both ideal and nonideal $\mathrm{MO}_{\mathrm{X}}$ types as seen from Figures 1 and 2.

3.1. Potential across Helmholtz Layer Capacitance. The nonfaradaic processes have been captured using the same TLM as the basis. It is to be noted that the TLM is a general thermodynamic model that is used to specifically capture the adsorption of electrolyte ions to $\mathrm{MO}_{X}$ surfaces [33] and also the protonation/deprotonation reactions that occur on the electrode surface. The $\mathrm{MO}_{X}$ surface is occupied by hydroxyl groups due to the dissociative adsorption of water followed by proton displacement [34]. This process is more prevalent for the ideal type of $\mathrm{MO}_{X}$ such as $\mathrm{RuO}_{2}$, resulting in a larger amount of hydroxyl groups in these oxides. An equilibrium similar to the above equations (2) and (3) was developed as follows:

$$
\begin{gathered}
\mathrm{SOH} \stackrel{K_{1}}{\rightleftharpoons} \mathrm{SO}^{-}+H_{\mathrm{s}}^{+}, \\
\mathrm{SOH}_{2}^{+} \stackrel{K_{2}}{\rightleftharpoons} \mathrm{SOH}+H_{\mathrm{s}}^{+},
\end{gathered}
$$

where $K_{1}$ and $K_{2}$ represent the equilibrium constants for the deprotonation and protonation reactions, respectively. The adsorbed hydrogen ions, $\mathrm{H}_{\mathrm{s}}^{+}$, can be expressed in the following using the Boltzmann relation: 


$$
\left[H_{s}^{+}\right]=\left[\mathrm{H}^{+}\right] \exp \left(-\frac{e \psi_{0}}{k T}\right),
$$

where $\psi_{0}$ represents the potential at 0 -plane, while $e, k$, and $T$ represent the elementary charge of a particle, Boltzmann constant, and temperature, respectively. Substituting equations (6) and (8) and equations (7) and (8), the expressions for $K_{1}$ and $K_{2}$ can be derived as follows:

$$
\begin{aligned}
& K_{1}=\frac{\left[\mathrm{SO}^{-}\right]\left[\mathrm{H}^{+}\right]}{[\mathrm{SOH}]} \cdot \exp \left(-\frac{e \psi_{0}}{k T}\right), \\
& K_{2}=\frac{[\mathrm{SOH}]\left[\mathrm{H}^{+}\right]}{\left[\mathrm{SOH}_{2}^{+}\right]} \cdot \exp \left(-\frac{e \psi_{0}}{k T}\right) .
\end{aligned}
$$

Surface complexation reactions occur between species such as $\mathrm{SO}^{-}$and $\mathrm{SOH}_{2}^{+}$and electrolyte ions that are present. The equilibrium is expressed in the following with $K_{s}^{+}$and $\mathrm{Cl}_{s}^{-}$represented as the adsorbed electrolyte ions:

$$
\begin{gathered}
\mathrm{SOH}_{2}^{+} \mathrm{Cl}^{-} \stackrel{K_{\text {ani }}}{\rightleftharpoons} \mathrm{SOH}_{2}^{+}+\mathrm{Cl}_{\mathrm{s}}^{-}, \\
\mathrm{SO}^{-} \mathrm{K}^{+} \stackrel{K_{\text {cat }}}{\rightleftharpoons} \mathrm{SO}^{-}+K_{\mathrm{s}}^{+},
\end{gathered}
$$

where $K_{\text {ani }}$ and $K_{\text {cat }}$ represent the equilibrium constants of the respective surface complexation reactions. Similar to the adsorbed hydrogen ions, the adsorbed electrolyte ions, $K_{s}^{+}$ and $\mathrm{Cl}_{\mathrm{s}}^{-}$, can be represented using the Boltzmann relation as follows:

$$
\begin{aligned}
& {\left[K_{\mathrm{s}}^{+}\right]=\left[\mathrm{K}^{+}\right] \exp \left(-\frac{e \psi_{\beta}}{k T}\right),} \\
& {\left[\mathrm{Cl}_{\mathrm{s}}^{-}\right]=\left[\mathrm{Cl}^{-}\right] \exp \left(-\frac{e \psi_{\beta}}{k T}\right),}
\end{aligned}
$$

where $\psi_{\beta}$ represents the potential at the $\beta$-plane. Substituting equations (11) and (14) and equations (12) and (13), the expressions for $K_{\mathrm{ani}}$ and $K_{\mathrm{cat}}$ can be derived as follows:

$$
\begin{aligned}
& K_{\mathrm{cat}}=\frac{\left[\mathrm{SO}^{-}\right]\left[\mathrm{K}^{+}\right]}{\left[\mathrm{SO}^{-} \mathrm{K}^{+}\right]} \cdot \exp \left(-\frac{e \psi_{\beta}}{k T}\right), \\
& K_{\mathrm{ani}}=\frac{\left[\mathrm{SOH}_{2}^{+}\right]\left[\mathrm{Cl}^{-}\right]}{\left[\mathrm{SOH}_{2}^{+} \mathrm{Cl}^{-}\right]} \cdot \exp \left(-\frac{e \psi_{\beta}}{k T}\right) .
\end{aligned}
$$

Combining the surface protonation/deprotonation reactions with the surface complexation reactions, expressions which relate the hydroxyl groups $(\mathrm{SOH})$ with the adsorbed electrolyte ions and hydrogen ions can be derived as follows:

$$
\begin{aligned}
& \mathrm{SOH}+K_{\mathrm{s}}^{+} \stackrel{K_{1}^{*}}{\rightleftharpoons} \mathrm{SO}^{-} \mathrm{K}^{+}+H_{\mathrm{s}}^{+}, \\
& \mathrm{SOH}_{2}^{+} \mathrm{Cl}^{-} \stackrel{K_{2}^{*}}{\rightleftharpoons} \mathrm{SOH}+H_{\mathrm{s}}^{+}+\mathrm{Cl}_{\mathrm{s}}^{-},
\end{aligned}
$$

where $\mathrm{K}_{1}^{*}$ and $\mathrm{K}_{2}^{*}$ represent the equilibrium constants for these reactions. These equilibrium constants can be expressed using the Boltzmann expansion:

$$
\begin{aligned}
& K_{1}^{*}=\frac{\left[\mathrm{SO}^{-} \mathrm{K}^{+}\right]\left[\mathrm{H}^{+}\right] \exp \left(-(e / k T)\left(\psi_{0}-\psi_{\beta}\right)\right)}{[\mathrm{SOH}]\left[\mathrm{K}^{+}\right]}=\frac{K_{1}}{K_{\mathrm{cat}}}, \\
& K_{2}^{*}=\frac{[\mathrm{SOH}]\left[\mathrm{H}^{+}\right]\left[\mathrm{Cl}^{-}\right] \exp \left(-(e / k T)\left(\psi_{0}+\psi_{\beta}\right)\right)}{\left[\mathrm{SOH}_{2}^{+} \mathrm{Cl}^{-}\right]}=K_{2} \cdot K_{\mathrm{ani}},
\end{aligned}
$$

The TLM is thus particularly applicable to model the $\mathrm{pH}$ response mechanism of metal oxide electrode surfaces. $\psi_{0}$, $\psi_{\beta}$, and $\psi_{d}$ represent the potentials in the 0-plane, $\beta$-plane, and $d$-plane, respectively. $\psi_{0}$ represents the sum of the potential drops across the Helmholtz capacitance $\left(C_{\mathrm{H}}\right)$ and Gouy diffuse-layer capacitance $\left(C_{\mathrm{G}}\right)$.

$\sigma_{0}$ and $\sigma_{\beta}$ represent the charge densities in the 0-plane and $\beta$-plane. They can be expressed as follows:

$$
\begin{aligned}
& \sigma_{0}=B\left(\left[\mathrm{SOH}_{2}^{+}\right]+\left[\mathrm{SOH}_{2}^{+} \mathrm{Cl}^{-}\right]-\left[\mathrm{SO}^{-}\right]-\left[\mathrm{SO}^{-} \mathrm{K}^{+}\right]\right), \\
& \sigma_{\beta}=B\left(\left[\mathrm{SO}^{-} \mathrm{K}^{+}\right]-\left[\mathrm{SOH}_{2}^{+} \mathrm{Cl}^{-}\right]\right),
\end{aligned}
$$

where $B$ can be expressed as

$$
B=\frac{10^{6} F}{A}=96485 \frac{\mu C}{\mathrm{~cm}^{2}},
$$

where $F$ represents Faraday's constant, while $A$ is the unit surface area of oxide available per unit volume of electrolyte solution. $\sigma_{d}$ represents the charge density at the $d$-plane, and it can be expressed as follows:

$$
\sigma_{d}=-11.74 C^{1 / 2} \sin h\left(\frac{z e \psi_{d}}{2 k T}\right) \frac{\mu C}{\mathrm{~cm}^{2}},
$$

where $C$ and $z$ represent the bulk concentration and charge of the electrolyte counterion under consideration in the diffuse layer. For electroneutrality to hold true, the following expression needs to be true:

$$
\sigma_{0}+\sigma_{\beta}+\sigma_{d}=0
$$

The inner Helmholtz layer, represented as the intervening gap between the 0 -plane and $\beta$ plane, holds a capacitance of $C_{1}$. The outer Helmholtz layer, represented as the intervening gap between the $\beta$-plane and $d$-plane, holds a capacitance of $C_{2}$. According to the TLM, these capacitances are assumed to be constant in the regions between the planes [28]. This allows for the potential in the planes to be related to the charge densities according to the following relationships:

$$
\begin{aligned}
& \psi_{0}-\psi_{\beta}=\frac{\sigma_{0}}{C_{1}}, \\
& \psi_{\beta}-\psi_{d}=-\frac{\sigma_{d}}{C_{2}} .
\end{aligned}
$$

Using the surface mass balance, the surface site densities $\left(N_{s}\right)$ are related to the concentrations of various electrode surface species as follows: 


$$
N_{s}=B\left(\left[\mathrm{SOH}_{2}^{+}\right]+\left[\mathrm{SOH}_{2}^{+} \mathrm{Cl}^{-}\right]+[\mathrm{SOH}]+\left[\mathrm{SO}^{-} \mathrm{K}^{+}\right]+\left[\mathrm{SO}^{-}\right]\right) .
$$

Equations (9), (10), (19), and (20) can be rewritten in terms of the concentrations of surface species as shown in the following:

$$
\begin{aligned}
{\left[\mathrm{SO}^{-}\right] } & =\frac{[\mathrm{SOH}] \cdot K_{1}}{\left[\mathrm{H}^{+}\right] \cdot \exp \left(-\left(e \psi_{0} / k T\right)\right)}, \\
{\left[\mathrm{SOH}_{2}^{+}\right] } & =\frac{[\mathrm{SOH}]\left[\mathrm{H}^{+}\right] \exp \left(-\left(e \psi_{0} / k T\right)\right)}{K_{2}} \\
{\left[\mathrm{SO}^{-} \mathrm{K}^{+}\right] } & =\frac{[\mathrm{SOH}]\left[\mathrm{K}^{+}\right] \exp \left(-(e / k T)\left(\psi_{0}-\psi_{\beta}\right)\right) K_{1}^{*}}{\left[\mathrm{H}^{+}\right]}, \\
{\left[\mathrm{SOH}_{2}^{+} \mathrm{Cl}^{-}\right] } & =\frac{[\mathrm{SOH}]\left[\mathrm{H}^{+}\right]\left[\mathrm{Cl}^{-}\right] \exp \left(-(e / k T)\left(\psi_{\beta}-\psi_{0}\right)\right)}{K_{2}^{*}} .
\end{aligned}
$$

The TLM requires seven sets of parameters to be input, namely, the surface hydroxyl site density, $N_{s}$, the surface acidity equilibrium constants, $K_{1}$ and $K_{2}$, the complex ionization equilibrium constants, $K_{1}^{*}$ and $K_{2}^{*}$, and the inner and outer Helmholtz capacitances, $C_{1}$ and $C_{2}$. The surface acidity equilibrium constants, $K_{1}$ and $K_{2}$, can be theoretically derived for each $\mathrm{MO}_{\mathrm{X}}$ material as per the theoretical equations derived by Sverjensky and Sahai [25] and can be expressed in a manner consistent with the use of symbols and notations in this work as follows:

$$
\begin{aligned}
& K_{1}=-\left[21.1158\left(\frac{1}{\varepsilon_{s}}\right)-36.5688\left(\frac{s}{r_{\mathrm{MOH}}}\right)+16.4551\right], \\
& K_{2}=-\left[21.1158\left(\frac{1}{\varepsilon_{s}}\right)-49.2608\left(\frac{s}{r_{\mathrm{MOH}}}\right)+12.9181\right],
\end{aligned}
$$

where $\left(s / r_{\mathrm{MOH}}\right)$ represents a parameter which includes Pauling's bond length of the material $(s)$ and the metalhydroxyl bond length $\left(r_{\mathrm{MOH}}\right)$. This $r_{\mathrm{MOH}}$ was computed as the sum of the metal-oxygen bond length $\left(r_{\mathrm{MO}}\right)$ and the $\mathrm{O}-\mathrm{H}$ bond length which was fixed at $1.01 \mathrm{~A}^{\circ}$ [25].

The set of equations, equations (21)-(32), can be solved numerically for any $\mathrm{pH}$ value and concentration of electrolyte solution.

3.2. Potential across Space-Charge Layer Capacitance. The potential drop across the space-charge layer capacitance $\left(V_{\mathrm{SC}}\right)$ could be estimated by first focusing on the width of the space-charge layer. The expression for the width of the space-charge layer $(W)$ was derived by Al-Hilli and Willander [21] as seen in the following:

$$
W=\left[\frac{2 \varepsilon_{0} \varepsilon_{s}}{e N_{d}}\left(V-V_{\mathrm{fb}}-\frac{k T}{q}\right)\right]^{1 / 2},
$$

where $\varepsilon_{0}$ is the permittivity of vacuum, $\varepsilon_{s}$ is the dielectric constant of the semiconductor, $N_{D}$ is the density of an electron donor, $V$ is the electrode potential, and $V_{\mathrm{fb}}$ is the flat-band potential. To estimate the value of $N_{D}$, the total volume of a unit cell, $v$, of $\mathrm{MO}_{X}$ in the study was obtained using the lattice parameters of the unit cell as expressed in the following:

$$
v=\lambda_{a} \cdot \lambda_{b} \cdot \lambda_{c}
$$

The lattice parameters $\left(\lambda_{a}, \lambda_{b}\right.$, and $\left.\lambda_{c}\right)$ are tabulated in Table $1 . N_{\mathrm{D}}$ can thus be expressed as follows:

$$
N_{d}=\tau \cdot \omega \cdot v \cdot \kappa,
$$

where $\tau, \omega$, and $\kappa$ represent the oxygen vacancy percentage, number of oxygen atoms per unit cell, and number of carriers per vacancy, respectively. The $\tau$-value was fixed at $2.5 \%$ as it was a physically realizable vacancy concentration [40] for $\mathrm{MO}_{X}$. The $\kappa$-value was fixed at a value of 2 as there were two electron carriers for every oxygen vacancy. The total number of oxygen atoms per unit cell $\omega$ for every $\mathrm{MO}_{X}$ considered in this work is tabulated in Table 1. Al-Hilli and Willander [21] represented $V(0)$, the potential at the electrode surface $(x=0)$, as follows:

$$
V(0)=\frac{q N_{d} W}{\varepsilon_{0} \varepsilon_{s}} \cdot \delta,
$$

where $\delta$ represents the width of the Helmholtz layer. $\delta$ can be expressed according to Gongadze et al. [41] as follows:

$$
\delta=\frac{\varepsilon_{0} \cdot \varepsilon_{r}}{C_{1}+C_{2}}
$$

where $\varepsilon_{r}$ represents the dielectric constant of the electrolyte solution, and this is tabulated in Table 1. The Helmholtz layer capacitance, $C_{\mathrm{H}}$, is represented as the sum of the inner and outer Helmholtz layer capacitances $\left(C_{1}\right.$ and $\left.C_{2}\right)$. The potential at the 0 -plane as captured in the TLM, $\psi_{0}$, can be related to $V(0)$ as follows:

$$
V(0)=-\psi_{0}=\frac{q N_{d} W}{\varepsilon_{0} \varepsilon_{s}} \cdot \delta .
$$

Assuming $\quad V-V_{\mathrm{fb}}=V_{\mathrm{SC}}$, equation (40) can be substituted into equation (35) allowing $V_{\mathrm{SC}}$ to be expressed as follows:

$$
V_{\mathrm{SC}}=\frac{1}{e}\left[\frac{\psi_{0}^{2} \varepsilon_{0} \varepsilon_{s}+2 \delta^{2} k T N_{d}}{2 \delta^{2} N_{d}}\right] .
$$

The sum of the potentials across the Helmholtz layer and the space-charge layer is taken as the total electrode potential, $\xi$ :

$$
\xi=V_{\mathrm{H}}+V_{\mathrm{SC}}
$$

The contribution to the total electrode potential by surface states has not been considered in this engineering 
TABLE 1: Space-charge layer model parameters.

\begin{tabular}{lcccccc}
\hline $\mathrm{MO}_{X}$ & $\lambda_{a}\left(\mathrm{~A}^{\circ}\right)$ & $\lambda_{b}\left(\mathrm{~A}^{\circ}\right)$ & $\lambda_{c}\left(\mathrm{~A}^{\circ}\right)$ & $\omega$ & $\varepsilon_{r}$ & Phase \\
\hline $\mathrm{RuO}_{2}$ & $4.49[35]$ & $4.49[35]$ & $3.10[35]$ & 4 & 78.2 & Rutile \\
$\mathrm{TiO}_{2}$ & $4.59[36]$ & $4.59[36]$ & $2.96[36]$ & 4 & 78.2 & Rutile \\
$\mathrm{TiO}_{2}$ & $3.79[37]$ & $3.79[37]$ & $3.79[37]$ & 4 & 78.2 & Anatase/low-temp. annealing structure \\
$\mathrm{Ta}_{2} \mathrm{O}_{5}$ & $7.19[38]$ & $7.19[38]$ & $3.83[38]$ & 10 & 78.2 & All \\
$\mathrm{Al}_{2} \mathrm{O}_{3}$ & $7.90[39]$ & $7.90[39]$ & $7.90[39]$ & 6 & 78.2 & All \\
\hline
\end{tabular}

model. The total electrode potential is calculated for each $\mathrm{pH}$ value across the $\mathrm{pH}$ range that is analysed. The calculated electrode potentials against $\mathrm{pH}$ are plotted, and a linear regression fit is used to model the dataset. The slope of the linear regression fit obtained is represented as the predicted sensitivity of the $\mathrm{MO}_{X}$ electrode material in the study. This study analyses four different metal oxides, $\mathrm{RuO}_{2}, \mathrm{TiO}_{2}$, $\mathrm{Ta}_{2} \mathrm{O}_{5}$, and $\mathrm{Al}_{2} \mathrm{O}_{3}$, and their respective different phases which were controlled by their fabrication method temperature.

\section{Methodology}

4.1. Total Electrode Potential against $p H$ Variation. To analyse the potentiometric sensitivity of the $\mathrm{pH}$ sensor, it is necessary to determine the total electrode potential, $\xi$, of the metal oxide $\mathrm{pH}$ sensor. This could be expressed as the sum of the potential differences across the Helmholtz layer and the interface as shown in equation (42).

The potential across the Helmholtz layer $V_{\mathrm{H}}$ can be determined by numerically solving the set of equations (21)-(32) for each varying $\mathrm{pH}$ value, using a nonlinear solver. In this work, Python's "fsolve," which implements the dogleg numerical methods, has been used for the purpose. The potential difference across the space-charge layer can then be calculated from equation (41).

By plotting the total electrode potential against $\mathrm{pH}$, the sensitivity of the $\mathrm{MO}_{\mathrm{X}} \mathrm{pH}$ sensor could be determined for a particular set of parameters that is input into the TLM. Extreme acidic and alkaline $\mathrm{pH}$ regimes have been excluded. A pH range of 2 to 11 has been chosen for this analysis. With the exception of $C_{1}$, the rest of the TLM parameters discussed in Section 4.1 were kept constant for each experimental run. These parameters are tabulated in Table 2. Furthermore, the intrinsic parameters that are required to determine the surface acidity equilibrium constants according to equations (33) and (34) are also provided in Table 2.

The complex ionization equilibrium constants were calculated using equations (19) and (20) with corresponding surface acidity equilibrium constants and electrolyte adsorption equilibrium constants, $K_{\text {cat }}$ and $K_{\text {ani }} \cdot \log K_{\text {cat }}$ and $\log K_{\text {ani }}$ were fixed at 1.9 and 2.2 , as derived from literature [28], for electrolyte $\mathrm{KCl}$ which was taken as the electrolyte in the study for all the experimental runs.

The outer layer Helmholtz capacitance $C_{2}$ was kept constant at $20 \mu \mathrm{F} / \mathrm{cm}^{2}$ for every run as it was considered an invariant across different metal oxide electrodes [57]. Since the fabrication temperature governs the number of surface hydroxyl sites present on a metal oxide electrode [20], it was imperative to vary the hydroxyl site density values, $N_{s}$, for metal oxides wherever applicable. $\mathrm{RuO}_{2}$, low band-gap metal oxide known for excellent $\mathrm{pH}$ sensitivity [58], has a tendency to have higher $N_{s}$ values since water dissociation on $\mathrm{RuO}_{2}$ rutile surfaces tends to form greater amounts of hydroxyl groups than other rutile surfaces such as $\mathrm{TiO}_{2}$, for instance [59].

Furthermore, the hydrated and unhydrated forms of $\mathrm{RuO}_{2}$ tend to have different site densities. The site density for the unhydrated form of $\mathrm{RuO}_{2}$ of 12.642 sites $/ \mathrm{nm}^{2}$ has been extracted directly from literature [42]. To estimate the site density of a hydrated form of $\mathrm{RuO}_{2}$, the contribution to the site density from water dissociation reactions was added to the site density of unhydrated metal oxide. To do this, the amount of water molecules that typically adsorb on rutile surfaces (0.05 water $\left./ \mathrm{A}^{\circ}\right)[60]$ and the percentage of water dissociation that occurs on the surface of rutile $\mathrm{RuO}_{2}$ (50\%) [59] were extracted from the literature. The product of these values is multiplied by 2 to represent the fact that two hydroxyl groups are formed for every water molecule that gets dissociated. This leads to an addition of 5 sites $/ \mathrm{nm}^{2}$ to the unhydrated site density, resulting in a total of $17.642 \mathrm{sites} / \mathrm{nm}^{2}$. These variations have been captured in the experimental runs. For $\mathrm{Ta}_{2} \mathrm{O}_{5}$ and $\mathrm{Al}_{2} \mathrm{O}_{3}$, two different regimes of phases, namely, lowtemperature-annealed polycrystalline and high-temperature-annealed polycrystalline phases, were captured with higher site density and lower site density values, respectively. Since there are no concrete experimental data for the site density values of $\mathrm{Ta}_{2} \mathrm{O}_{5}$, two different site density values of 10 sites $/ \mathrm{nm}^{2}$ and 12 sites $/ \mathrm{nm}^{2}$ were tried in the low-temperature-annealed regime. Two different site density values of 4 and 6 sites $/ \mathrm{nm}^{2}$ were tried in the high-temperature-annealed regime. A lack of consensus among experimenters with regard to site density values for $\mathrm{TiO}_{2}$ is evident with a wide range of values suggested by experimenters [52].

Furthermore, it is evident from the literature that surface hydroxyl groups decreased with annealing temperature which resulted in the three distinct phases of $\mathrm{TiO}_{2}$, rutile, anatase, and low-temperature-annealed polycrystalline phases, to be modelled with increasing site density values. Two different site densities, 2.7 and 5 sites $/ \mathrm{nm}^{2}$, were tried for the rutile phase, while a single-site density of 7 sites $/ \mathrm{nm}^{2}$ and 12.5 sites $/ \mathrm{nm}^{2}$ was tried for the anatase and low-temperature-annealed polycrystalline phase, respectively.

Appropriate values of the static dielectric constant, $\varepsilon_{s}$, were extracted from the literature for the respective phases as seen in Table 2. For $\mathrm{TiO}_{2}$, the $\varepsilon_{s}$ value for the low-temperatureannealed polycrystalline phase was estimated to be similar to 
TABLE 2: TLM and Sverjensky model parameters.

\begin{tabular}{|c|c|c|c|c|c|c|c|c|c|c|}
\hline $\mathrm{MO}_{X}$ & Electrolyte & $N_{s}$ & $\varepsilon_{s}$ & $\left(s / r_{\mathrm{MOH}}\right)^{\mathrm{b}}$ & $\log K_{1}$ & $\log K_{2}$ & $\log K_{\text {cat }}$ & $\log K_{\text {ani }}$ & $\log K_{1}^{*}$ & $\log K_{2}^{*}$ \\
\hline $\mathrm{RuO}_{2}$ & $\mathrm{KCl}$ & $\begin{array}{c}12.6[42] \\
17.6\end{array}$ & $55.2[43]$ & $0.2257[44,45]$ & 8.5845 & 2.1831 & 1.9 & 2.2 & 6.6845 & 4.3831 \\
\hline $\mathrm{Ta}_{2} \mathrm{O}_{5}$ & $\mathrm{KCl}$ & $\begin{array}{c}4 \\
6 \\
10[49] \\
12[51] \\
\end{array}$ & $\begin{array}{l}50[46] \\
25[46]\end{array}$ & $\begin{array}{c}0.2625[39,47,48] \\
0.2581[39,50]\end{array}$ & $\begin{array}{l}7.2768 \\
7.8602\end{array}$ & 0.4077 & 1.9 & 2.2 & 5.3768 & 2.6077 \\
\hline $\mathrm{TiO}_{2}$ & $\mathrm{NaCl}^{\mathrm{a}}$ & $\begin{array}{c}2.7[52] \\
5 \\
7 \\
12.5[52] \\
12.5 \\
\end{array}$ & $\begin{array}{c}35[53] \\
35 \\
35\end{array}$ & $\begin{array}{c}0.2264[54,55] \\
0.2260[54,55] \\
-\end{array}$ & $\begin{array}{l}8.7802 \\
8.7943 \\
8.6000 \\
\end{array}$ & $\begin{array}{l}2.3701 \\
2.3890 \\
2.2000\end{array}$ & $\begin{array}{l}1.9 \\
1.9 \\
2.5\end{array}$ & $\begin{array}{l}2.2 \\
2.2 \\
2.3\end{array}$ & $\begin{array}{l}6.8802 \\
6.8943 \\
6.1000 \\
\end{array}$ & $\begin{array}{l}4.5701 \\
4.5890 \\
4.5000 \\
\end{array}$ \\
\hline $\mathrm{Al}_{2} \mathrm{O}_{3}$ & $\mathrm{KCl}$ & $\begin{array}{c}12.04[51] \\
1.3[56] \\
\end{array}$ & $10.43[25]$ & $0.1913[25]$ & 11.4840 & 5.5190 & 1.9 & 2.2 & 9.5840 & 7.7190 \\
\hline
\end{tabular}

${ }^{\mathrm{a}}$ Experimental run conducted using the $C_{1}$ capacitance of $120 \mu \mathrm{F}$ as specified by Dimitri [30]. ${ }^{\mathrm{b}}$ The first reference cited is for the $\mathrm{MO}_{X}$ coordination number for determining $s$. Subsequent references are for determining the metal-oxygen bond length $\left(r_{\mathrm{MO}}\right)$.

that of the anatase phase [61]. In a separate analysis, it was found that the variation of the $\varepsilon_{s}$ value has a very marginal impact on the $\psi_{0}$ value when applying the TLM and thus has limited impact on the sensitivity performance of the $\mathrm{pH}$ sensor.

\subsection{Determination of $C_{1}$ Helmholtz Inner Layer Capacitance.} The Helmholtz inner layer capacitance, $C_{1}$, is a parameter of the TLM that does not have any robust, predictive, theoretical estimation procedures that could be used. Preliminary attempts have been made by theoreticians such as Sverjensky and Sahai and Dimitri $[25,30]$ by using electrostatic and solvation theories to estimate $C_{1}$ capacitances for different metal oxide and electrolyte combinations. Others, such as Yates et al. [62], assumed a value of $C_{1}$ capacitance to be of a fixed value across all oxides and electrolytes to achieve agreement between calculations and experimentally derived values of surface charge, $\sigma_{0}$, and diffuse-layer potential, $\psi_{d}$, data.

However, these methods to determine $C_{1}$ capacitance do not incorporate the notion of invariant $\mathrm{pH}$ sensitivity across different ionic strengths of the electrolyte solutions. In experimental studies of metal oxide $\mathrm{pH}$ sensors, the sensitivities are expressed in terms of the Nernstian expression [10]. The Nernstian expression, being primarily redox-based, does not include ionic strength variation effects on $\mathrm{pH}$ sensitivity. On the contrary, the TLM is primarily based on ion transfer reactions occurring on the surface of the metal oxide electrode, resulting in varying $\mathrm{pH}$ sensitivities across different ionic strengths of electrolyte solutions.

It was thus hypothesized that there should exist an ionic strength invariant sensitivity for some particular $C_{1}$ capacitance which overcomes the issue of different sensitivities being predicted by the TLM for different ionic strengths of the electrolyte solution. Therefore, the $C_{1}$ capacitance parameter in the TLM was varied over a wide range of values, and the corresponding $\mathrm{pH}$ sensitivity obtained was plotted as a function of $C_{1}$ capacitance. This procedure was repeated for multiple ionic strengths, namely, $0.1,0.3$, and $0.5 \mathrm{M}$, to cover the range for which the corresponding parameters such as surface acidity equilibrium constants $K_{1}$ and $K_{2}$ are valid [28].

This point of invariance could be observed at both low and high $C_{1}$ capacitance values. It is therefore imperative to discern which $C_{1}$ capacitance value provides the true ionic strength invariant $\mathrm{pH}$ sensitivity for a specific phase of a metal oxide. A metal oxide fabricated through high-temperature annealing would be expected to develop a greater Helmholtz capacitance in the electrolyte solution owing to its lower surface site density. A lower site density translates to lower active sites for protonation/deprotonation to take place. This allows for a buildup of charges along the inner and outer Helmholtz planes caused by the accumulation of ions from the bulk electrolyte solution. The buildup of these ions, which would have otherwise taken part in the ion transfer reactions, is a reason for the increase in $C_{1}$ capacitance in the hightemperature-annealed phase. Therefore, the $C_{1}$ capacitance range was varied according to the phase of the metal oxide.

For high-temperature-annealed metal oxides that are in the polycrystalline phase, the $C_{1}$ capacitance was varied over a wide range (from $10 \mu \mathrm{F} / \mathrm{cm}^{2}$ to $800 \mu \mathrm{F} / \mathrm{cm}^{2}$ in some cases) as these materials are known to be highly capacitive [63]. On the contrary, for low-temperature-annealed polycrystalline phase materials, the $C_{1}$ capacitance was varied over a relatively lower range (from $0.01 \mu \mathrm{F} / \mathrm{cm}^{2}$ to $150 \mu \mathrm{F} / \mathrm{cm}^{2}$ ). The threshold of $150 \mu \mathrm{F} / \mathrm{cm}^{2}$ was based on the maximum $C_{1}$ capacitance used in literature [28] for a similar study that involves the application of the TLM in the low-temperature annealing regimen.

\section{Results and Discussion}

5.1. Potentiometric Analysis Using $C_{1}$ Capacitances from the Literature. A theoretical potentiometric analysis was done by numerically solving the proposed engineering model for a $\mathrm{TiO}_{2}$ electrode based on parameters obtained from Dimitri [30], whose work suggested the use of $C_{1}$ capacitance of $120 \mu \mathrm{F} / \mathrm{cm}^{2}$ for that specific system. 
Figure 3 shows the total electrode potential $(\xi)$ plotted against $\mathrm{pH}$ across different ionic strengths $(0.1 \mathrm{M}, 0.3 \mathrm{M}$, and $0.5 \mathrm{M}$ ) for this system. Figure 3 shows excellent agreement of the data points to the linear regression fit line as seen from the high $R^{2}$ value of greater than 0.999 for all the electrolyte ionic strengths. The slopes of the three different ionic strength regimes are also different from one another with the $0.3 \mathrm{M}$ slope greater than the $0.1 \mathrm{M}$ slope by $5.93 \%$ and the $0.5 \mathrm{M}$ slope greater than $0.3 \mathrm{M}$ and $0.1 \mathrm{M}$ by $2.26 \%$ and $8.32 \%$, respectively. The $y$-intercepts of the linear regression fits are also different from one another with the $0.3 \mathrm{M}$ intercept greater than the $0.1 \mathrm{M}$ intercept by $5.45 \%$ and the $0.5 \mathrm{M}$ intercept greater than $0.3 \mathrm{M}$ and $0.1 \mathrm{M}$ by $2.07 \%$ and $7.63 \%$, respectively.

The slopes of the regression lines reflect the sensitivities of the $\mathrm{pH}$ sensors. It can be seen that there is an increasing trend of $\mathrm{pH}$ sensitivity with increasing ionic strengths while using Sverjensky's choice of $C_{1}$ capacitance value. This is not in consonance with the experimental setups which do not involve ionic strength variations of the electrolyte for $\mathrm{pH}$ sensitivity measurements. This is largely due to the fact that these measurements are based on the ideal Nernstian equation which does not involve electrolyte ionic strength variations. These results are to be expected since Sverjensky's work does not incorporate the notion of invariant $\mathrm{pH}$ sensitivity with differing electrolyte ionic strengths. It is also noteworthy that the predicted $\mathrm{pH}$ sensitivities are not in agreement with the experimentally observed value of $58.21 \mathrm{mV} / \mathrm{pH}$ [64] reported for the low-temperatureannealed $\mathrm{TiO}_{2}$ system.

5.2. $C_{1}$ Capacitance Variation. A wide range of $C_{1}$ capacitance values were applied into the TLM to obtain an invariant $\mathrm{pH}$ sensitivity across different ionic strengths. The range of $C_{1}$ capacitances used for high-temperature- and low-temperature-annealed phases was different in that a smaller range was required for low-temperature-annealed phases and a larger range for high-temperature-annealed phases.

The absolute slopes of the linear regression fits obtained were plotted against their respective $C_{1}$ capacitance values, for a range of $C_{1}$ capacitance values from 0 to $150 \mu \mathrm{F} / \mathrm{cm}^{2}$, across different ionic strengths $(0.1 \mathrm{M}, 0.3 \mathrm{M}$, and $0.5 \mathrm{M})$ for $\mathrm{TiO}_{2}, \mathrm{Ta}_{2} \mathrm{O}_{5}$, and $\mathrm{Al}_{2} \mathrm{O}_{3}$ as seen in Figure 4. A polynomial ninth-order fit was applied to each dataset with $R^{2}$ values exceeding 0.999 for every fit.

The absolute sensitivity of the metal oxide electrode is observed to decrease with increasing $C_{1}$ capacitance values. There is a rapid drop in sensitivity from 0 to $10 \mu \mathrm{F} / \mathrm{cm}^{2}$ followed by a gradual drop with increasing capacitance. The drop in sensitivity is observed to be greater at lower ionic strengths across the three metal oxides. The regression fits for the three ionic strengths $(0.1 \mathrm{M}, 0.3 \mathrm{M}$, and $0.5 \mathrm{M})$ are observed to intersect at a low capacitance value with a corresponding $\mathrm{pH}$ sensitivity of 59.1080, 59.1081, 59.1075, and $59.1050 \mathrm{mV} / \mathrm{pH}$ for $\mathrm{TiO}_{2}, \mathrm{Ta}_{2} \mathrm{O}_{5}\left(N_{s}=10\right), \mathrm{Ta}_{2} \mathrm{O}_{5}$ $\left(N_{s}=12\right)$, and $\mathrm{Al}_{2} \mathrm{O}_{3}$, respectively. The exact $C_{1}$ capacitances at which this invariant sensitivity is achieved are reported in

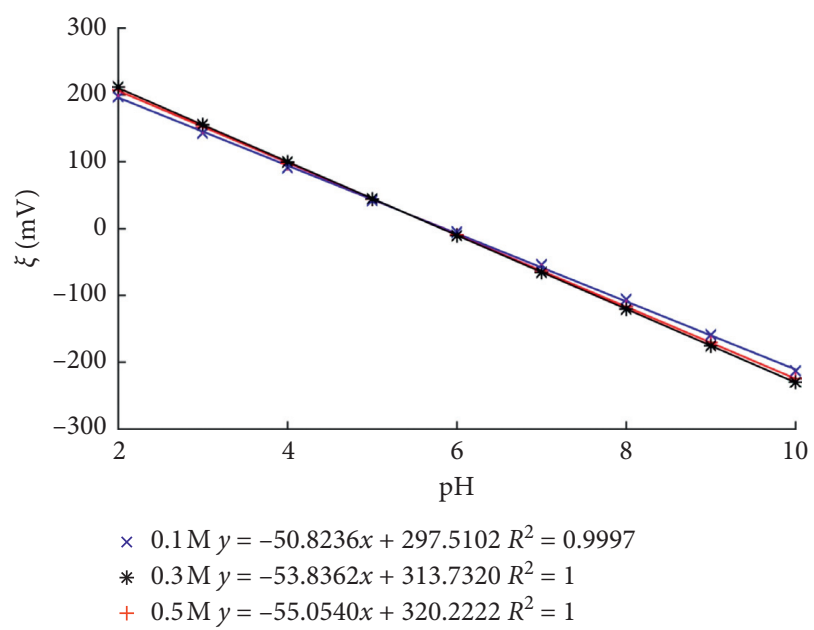

FIgURE 3: Total electrode potential $\xi$ against $\mathrm{pH}$ at $120 \mu \mathrm{F} / \mathrm{cm}^{2}$ based on parameters from Dimitri [30] for different electrolyte ionic strengths.

Table 3 . There is no variation in sensitivity across the metal oxides and marginal variation in $C_{1}$ capacitance values. It can also be observed that, among the three metal oxides, $\mathrm{Ta}_{2} \mathrm{O}_{5}\left(N_{s}=10\right)$ experiences the greatest drop in sensitivity across the capacitance range with a decrease of $13.869 \mathrm{mV} /$ $\mathrm{pH}$ across the range of $C_{1}$ capacitance as compared to $\mathrm{Ta}_{2} \mathrm{O}_{5}$ $\left(N_{s}=12\right)$ with a decrease of $12.712 \mathrm{mV} / \mathrm{pH}, \mathrm{TiO}_{2}$ with a decrease of $11.021 \mathrm{mV} / \mathrm{pH}$, and $\mathrm{Al}_{2} \mathrm{O}_{3}$ with a decrease of $7.041 \mathrm{mV} / \mathrm{pH}$.

An analysis similar to the above was performed for the high-temperature-annealed phases in that the absolute slopes of the linear regression fits of $\xi$ against $\mathrm{pH}$ analysis were plotted against their respective $C_{1}$ capacitance values across different ionic strengths $(0.1 \mathrm{M}, 0.3 \mathrm{M}$, and $0.5 \mathrm{M})$ for $\mathrm{RuO}_{2}, \mathrm{TiO}_{2}, \mathrm{Ta}_{2} \mathrm{O}_{5}$, and $\mathrm{Al}_{2} \mathrm{O}_{3}$ as seen in Figures 5 and 6. The same polynomial ninth-order fit was applied to each dataset with $R^{2}$ values exceeding 0.999 for every fit.

Similar to the low-temperature-annealed phase, the absolute sensitivity of the metal oxide electrode decreases with increasing capacitance value choice for the hightemperature-annealed phases. $\mathrm{RuO}_{2}$ displays a similar behaviour to its counterparts in the low-temperature-annealed phase in that there is a greater decrease in sensitivity with increasing capacitance value choice for a lower electrolyte ionic strength and a Nernstian $\mathrm{pH}$ sensitivity invariance point of $59.1094 \mathrm{mV} / \mathrm{pH}$ for a low $C_{1}$ capacitance. This is expected due to its high site densities $[42,66]$ even in its high-temperature-annealed rutile phase as compared to other metal oxides such as $\mathrm{TiO}_{2}$ [59]. Its exceptional $\mathrm{pH}$ sensitivity, as compared to other metal oxides, has been cited by many experimenters $[10,11]$. As expected, the hydrated $\mathrm{RuO}_{2}$ electrode was shown to have a marginal improvement in the sensitivity of $0.0012 \mathrm{mV} / \mathrm{pH}$ over the unhydrated $\mathrm{RuO}_{2}$ electrode. This improvement has also been reported in the literature although the improvement in sensitivity is observed to be greater in magnitude of around $3 \mathrm{mV} / \mathrm{pH}$. There may be several factors that are influenced by the fabrication procedure such as point and surface defects present on the electrode that could have contributed to the 


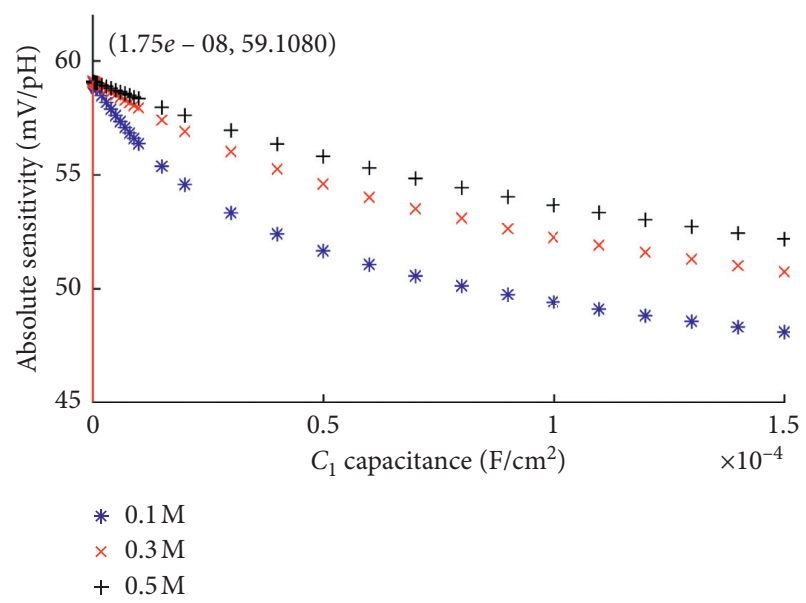

(a)

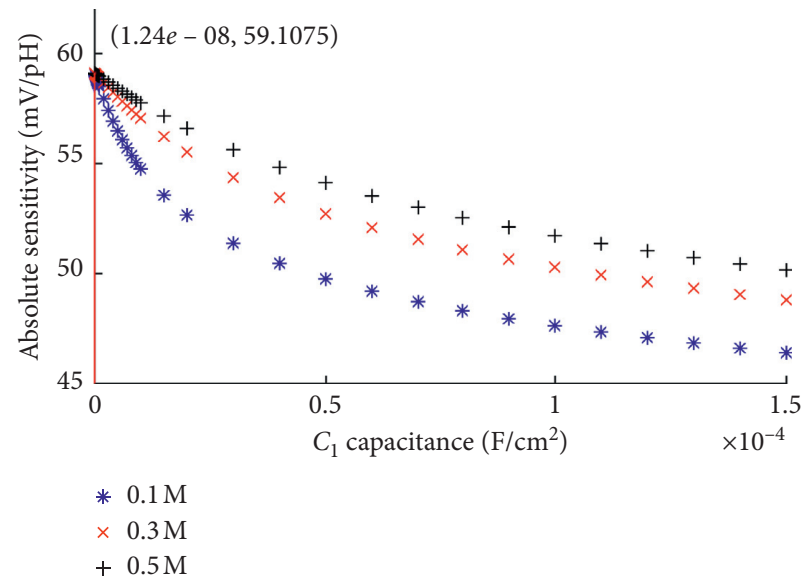

(c)

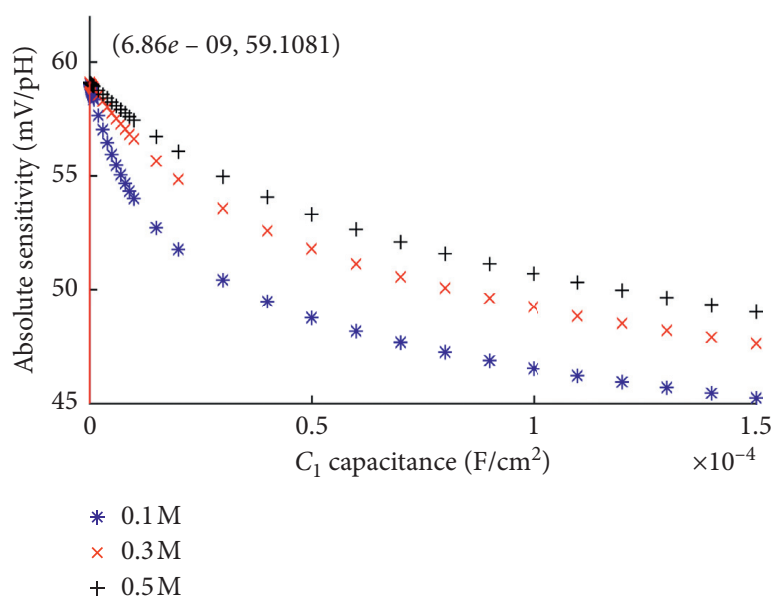

(b)

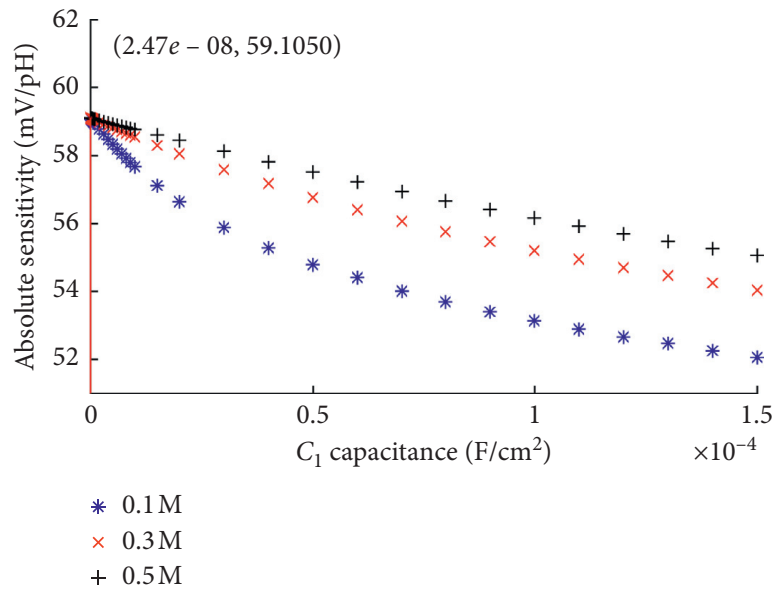

(d)

FIgURE 4: Absolute sensitivity against $C_{1}$ capacitance for (a) $\mathrm{TiO}_{2}, N_{s}: 12.5, \varepsilon_{s}: 35$, (b) $\mathrm{Ta}_{2} \mathrm{O}_{5}, N_{s}: 10, \varepsilon_{s}: 25,(\mathrm{c}) \mathrm{Ta}_{2} \mathrm{O}_{5}, N_{s}: 12$, $\varepsilon_{s}: 25$, and (d) $\mathrm{Al}_{2} \mathrm{O}_{3}, N_{s}: 12.04, \varepsilon_{s}: 10.43$. The electrolyte is $\mathrm{KCl}$ for all cases.

TABLE 3: Summary of $C_{1}$ capacitance variation model results.

\begin{tabular}{|c|c|c|c|c|c|c|c|c|c|}
\hline $\mathrm{MO}_{x}$ & Electrolyte & $\begin{array}{l}\text { Annealing } \\
\text { method }\end{array}$ & $\begin{array}{c}N_{s} \\
(\text { sites/ } \\
\left.\mathrm{nm}^{2}\right)\end{array}$ & $\mathcal{E}_{s}$ & pHpzc & $\begin{array}{c}C_{1} \times 10^{-6} \\
\left(\mathrm{~F} / \mathrm{cm}^{2}\right)\end{array}$ & $\begin{array}{c}\text { Calculated } \\
\text { absolute } \mathrm{pH} \\
\text { sensitivity }(\mathrm{mV} / \\
\mathrm{pH})\end{array}$ & $\begin{array}{c}\text { Experimental } \\
\text { absolute } \mathrm{pH} \\
\text { sensitivity }(\mathrm{mV} / \mathrm{pH})\end{array}$ & $\begin{array}{c}\% \text { difference between } \\
\text { calculated and } \\
\text { experimental results }\end{array}$ \\
\hline \multirow{2}{*}{$\mathrm{RuO}_{2}$} & \multirow{2}{*}{$\mathrm{KCl}$} & $\begin{array}{l}\text { High temp. } \\
\text { (unhydrated) }\end{array}$ & 12.6 & 55.2 & 5.526 & 0.0140 & 59.1082 & $57.0[11]$ & 3.699 \\
\hline & & $\begin{array}{l}\text { High temp. } \\
\text { (unhydrated) }\end{array}$ & 17.6 & 55.2 & 5.527 & 0.0197 & 59.1094 & $60.69[10]$ & 2.604 \\
\hline \multirow{4}{*}{$\mathrm{Ta}_{2} \mathrm{O}_{5}$} & \multirow{4}{*}{$\mathrm{KCl}$} & High temp. & 4 & 50 & 3.922 & 298.53 & 34.6144 & 35.3 [12] & 1.942 \\
\hline & & High temp. & 6 & 50 & 3.930 & 423.93 & 36.5067 & - & - \\
\hline & & Low temp. & 10 & 25 & 4.594 & 0.00686 & 59.1081 & 59.0 [9] & 0.183 \\
\hline & & Low temp. & 12 & 25 & 4.594 & 0.0124 & 59.1075 & $59.0[9]$ & 0.182 \\
\hline \multirow{4}{*}{$\mathrm{TiO}_{2}$} & \multirow{4}{*}{$\mathrm{KCl}$} & High temp. & 2.7 & 80 & 5.294 & 322.46 & 30.0011 & $30.0[8]$ & 0.004 \\
\hline & & High temp. & 5 & 80 & 5.283 & 518.7 & 33.9604 & - & \\
\hline & & High temp. & 7 & 35 & 5.618 & 728.21 & 35.5242 & $37.73[65]$ & 5.846 \\
\hline & & Low temp. & 12.5 & 35 & 5.733 & 0.0175 & 59.105 & $58.21[64]$ & 1.538 \\
\hline \multirow{2}{*}{$\mathrm{Al}_{2} \mathrm{O}_{3}$} & \multirow{2}{*}{$\mathrm{KCl}$} & Low temp. & 12.04 & 10.43 & 8.645 & 0.0247 & 59.105 & - & - \\
\hline & & High temp. & 1.3 & 10.43 & 8.777 & 130.83 & 29.6951 & - & - \\
\hline
\end{tabular}



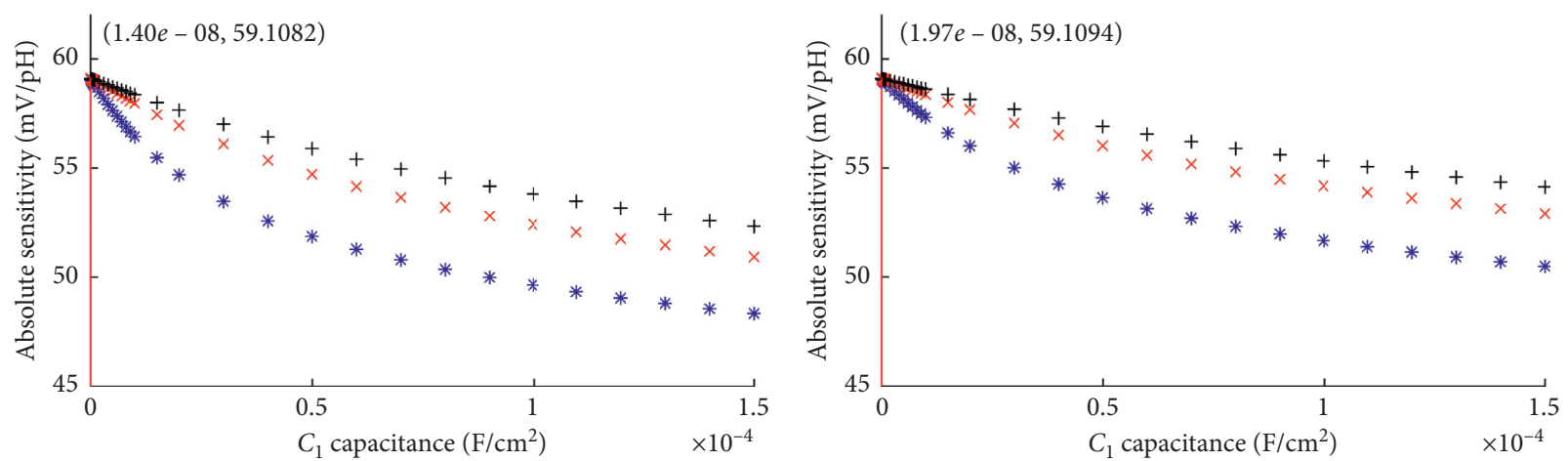

$$
\begin{array}{r}
* 0.1 \mathrm{M} \\
\times \quad 0.3 \mathrm{M}
\end{array}
$$$$
\text { * } 0.1 \mathrm{M}
$$$$
\times 0.3 \mathrm{M}
$$$$
+0.5 \mathrm{M}
$$

(a)
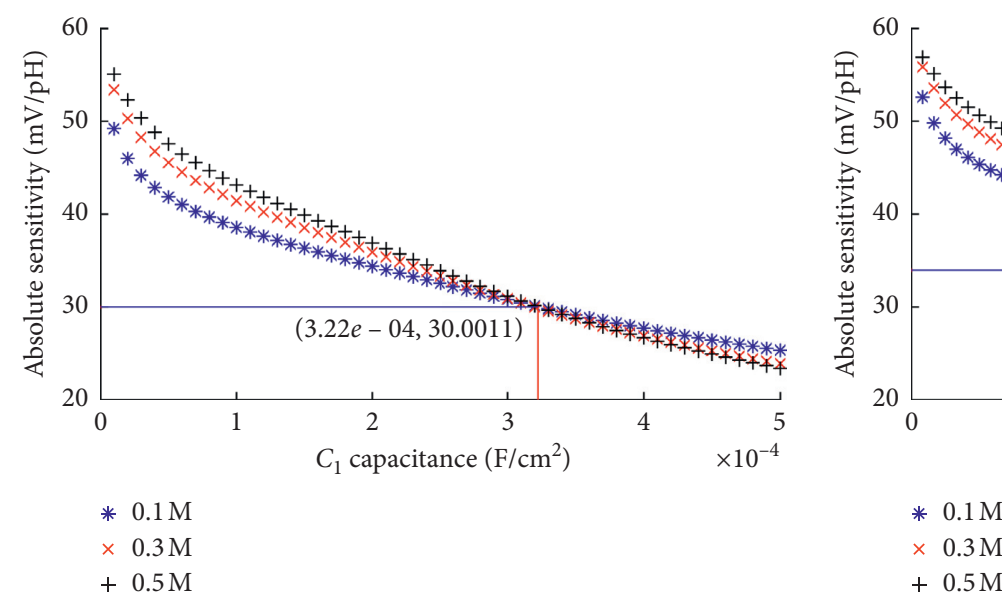

(b)

$$
\begin{aligned}
& * 0.1 \mathrm{M} \\
& \times 0.3 \mathrm{M} \\
& +0.5 \mathrm{M}
\end{aligned}
$$

(c)

(d)

Figure 5: Absolute sensitivity against $C_{1}$ capacitance for (a) $\mathrm{RuO}_{2}, N_{s}: 12.642$ (rutile: unhydrated), $\varepsilon_{s}: 55.23$, (b) $\mathrm{RuO}_{2}, N_{s}: 17.642$ (rutile: hydrated), $\varepsilon_{s}: 55.23$, (c) $\mathrm{TiO}_{2}$ (rutile), $N_{s}: 2.7, \varepsilon_{s}: 80$, and (d) $\mathrm{TiO}_{2}, N_{s}: 5$ (rutile), $\varepsilon_{s}: 80$. The electrolyte is $\mathrm{KCl}$ for all cases.

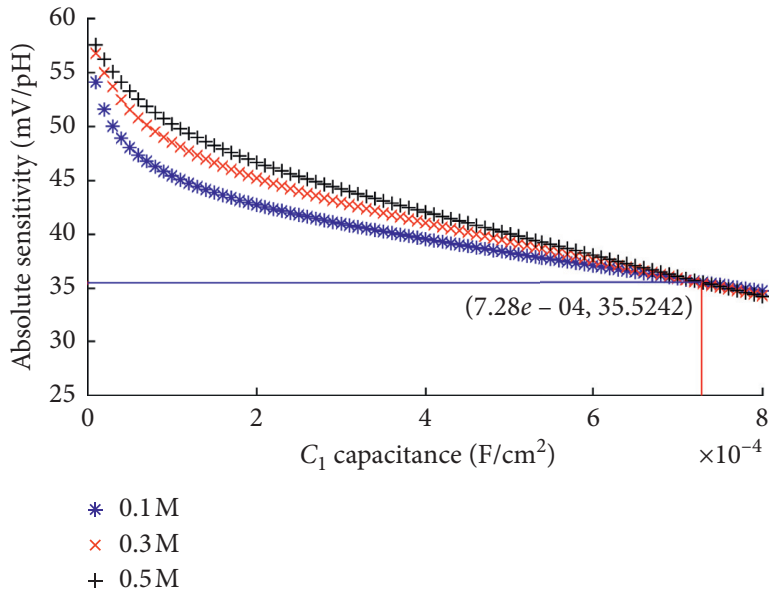

(a)

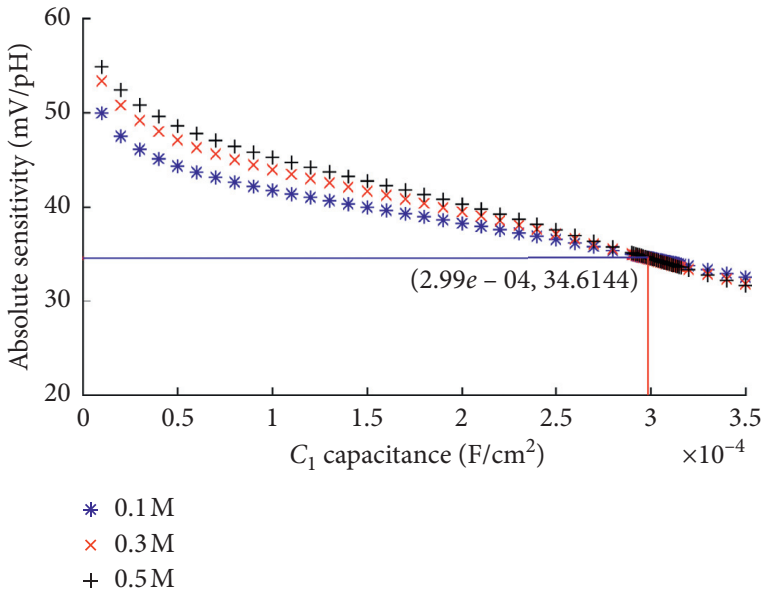

(b)

Figure 6: Continued. 


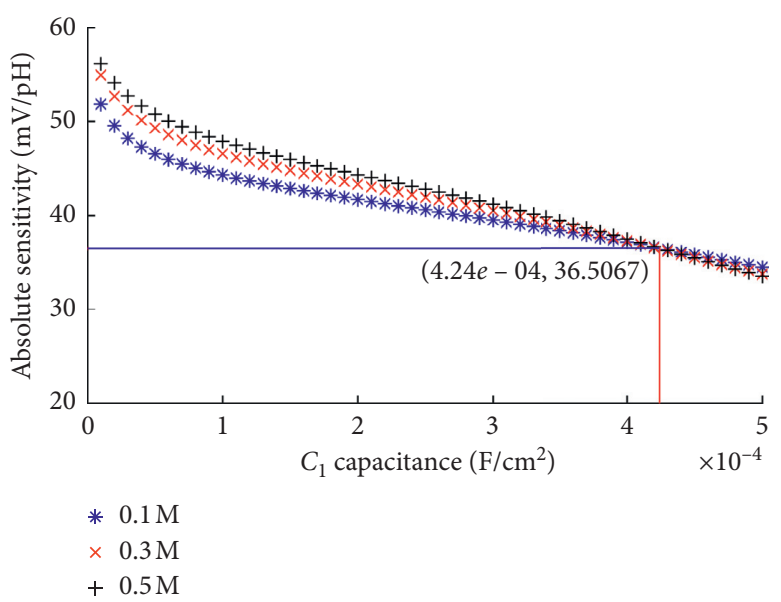

(c)

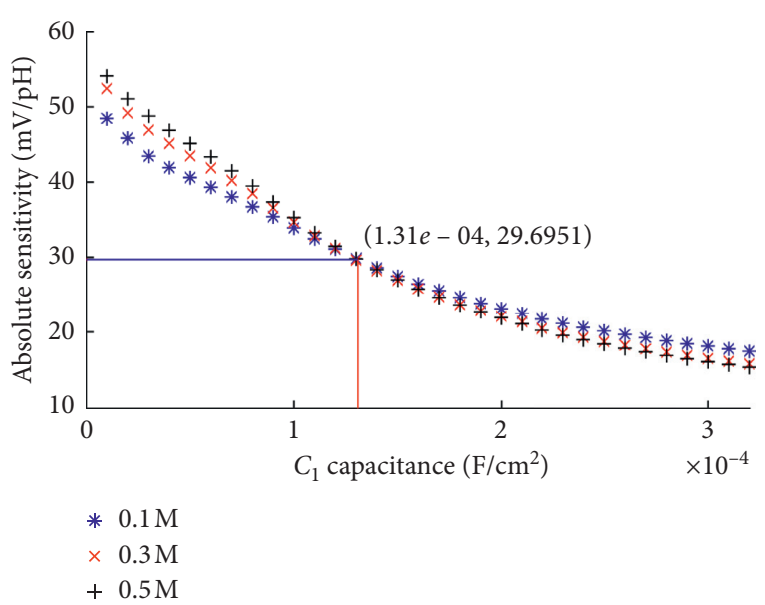

(d)

Figure 6: Absolute sensitivity against $C_{1}$ capacitance for (a) $\mathrm{TiO}_{2}, N_{s}: 7$ (anatase), $\varepsilon_{s}: 35$, (b) $\mathrm{Ta}_{2} \mathrm{O}_{5}, N_{s}: 4, \varepsilon_{s}: 50,(\mathrm{c}) \mathrm{Ta}_{2} \mathrm{O}_{5}, N_{s}: 6, \varepsilon_{s}: 50$, and (d) $\mathrm{Al}_{2} \mathrm{O}_{3}, N_{s}: 1.3, \varepsilon_{s}: 10.43$. The electrolyte is $\mathrm{KCl}$ for all cases.

increased sensitivity observed. The TLM and the determination of $K_{1}$ and $K_{2}$ involve only two parameters $\left(N_{s}\right.$ and $\left.\varepsilon_{s}\right)$ that reflects the fabrication process, and thus, minor variations from literature values are expected. Nevertheless, both theoretically derived sensitivities and those reported in the literature are observed to be close to the Nernstian value.

For the other metal oxides, a contrasting behaviour is observed to that of the low-temperature-annealed phase in that there is a greater decrease in $\mathrm{pH}$ sensitivity with increasing capacitance value choice for a higher electrolyte ionic strength. Furthermore, the $\mathrm{pH}$ sensitivity invariance point is observed at much higher $C_{1}$ capacitances. Therefore, the $\mathrm{pH}$ sensitivity is accordingly sub-Nernstian for these metal oxides in this phase.

For $\mathrm{TiO}_{2}$ and $\mathrm{Ta}_{2} \mathrm{O}_{5}$, it was observed that the variation of $N_{s}$ had an impact on the $\mathrm{pH}$ sensitivity. Lower $N_{s}$ resulted in a lower $\mathrm{pH}$ sensitivity and $C_{1}$ value. The sensitivities for $\mathrm{TiO}_{2}$ ranged from 30.0 to $35.5 \mathrm{mV} / \mathrm{pH}$ for $C_{1}$ ranging from 322 to $728 \mu \mathrm{F} / \mathrm{cm}^{2}$ for increasing $N_{s}$ values. The lower site density trial run for $\mathrm{Ta}_{2} \mathrm{O}_{5}$ had a $\mathrm{pH}$ sensitivity of $34.6 \mathrm{mV} / \mathrm{pH}$ and a $C_{1}$ value of $299 \mu \mathrm{F} / \mathrm{cm}^{2}$, while the higher site density run had a $\mathrm{pH}$ sensitivity of $36.5 \mathrm{mV} / \mathrm{pH}$ and a $C_{1}$ value of $424 \mu \mathrm{F} / \mathrm{cm}^{2}$. The single run conducted for $\mathrm{Al}_{2} \mathrm{O}_{3}$ yielded at a $\mathrm{pH}$ sensitivity of $29.7 \mathrm{mV} / \mathrm{pH}$ at a $C_{1}$ value of $131 \mu \mathrm{F} / \mathrm{cm}^{2}$. The results indicate that, among the high-temperature-annealed phases, $\mathrm{Al}_{2} \mathrm{O}_{3}$ is the least sensitive $\mathrm{pH}$ sensor, followed by $\mathrm{TiO}_{2}$ and $\mathrm{Ta}_{2} \mathrm{O}_{5}$. The results of these analyses along with their closest corresponding experimental sensitivities obtained from the literature are presented in Table 3 . The sensitivities obtained from the model are broadly within the range of values reported in the literature. For $\mathrm{Ta}_{2} \mathrm{O}_{5}$, the sensitivities obtained from the model were within the lower range of the literature values. The differences between the theoretical and experimental sensitivities could be attributed to potential defects present in the electrode. These defects may act as potential sites for hydroxyl groups to be present, resulting in an increase in site density and thus an increase in sensitivity. There may be several factors that are influenced by the fabrication procedure which are not captured by this model. This may in turn cause minor variations from literature values to be observed.

With increased $C_{1}$ capacitance effect, the ion transfer reactions (protonation/deprotonation) tend to be less effective in reflecting the $\mathrm{pH}$ change in the electrolyte solution. This is because a large $C_{1}$ capacitance effectively acts as a barrier to free ion transfer between the surface of the electrode and the $\beta$-layer. Since $\mathrm{pH}$ changes take place in the bulk electrolyte solution and the ion transfer reactions take place on the surface of the electrode, a large $C_{1}$ capacitance in the interface would prevent much of the ions present in the bulk electrolyte from reaching the electrode surface. This would cause a lower concentration of ions in the bulk to take part in the protonation/deprotonation reactions that take place on the electrode surface, resulting in a lower sensitivity to be observed with the increase in the $C_{1}$ capacitance effect. The behaviour of a greater decrease in $\mathrm{pH}$ sensitivity with increasing $C_{1}$ capacitance for lower electrolyte ionic strengths observed for low-temperature-annealed phases contrasts with the same behaviour observed with higher electrolyte ionic strengths for high-temperature-annealed phases. This serves as useful criteria to determine whether the invariant $\mathrm{pH}$ sensitivity would occur at a lower $C_{1} \mathrm{ca}-$ pacitance or at a higher $C_{1}$ capacitance choice. When greater decrease in $\mathrm{pH}$ sensitivity is observed for lower electrolyte ionic strengths, this indicates that an invariant $\mathrm{pH}$ sensitivity is likely to be found at low $C_{1}$ capacitance choice. On the contrary, greater decrease in $\mathrm{pH}$ sensitivity observed for higher electrolyte ionic strengths indicates that an invariant $\mathrm{pH}$ sensitivity is likely to be found at a higher $C_{1}$ capacitance value choice. Hence, $C_{1}$ capacitance value needs to be varied over a wider range to determine this sensitivity. It is noteworthy to mention that the sensitivities obtained from this analysis are in close agreement with published results from experiments conducted as seen in Table 3. Experimenters who used high-temperature annealing methods (over $850^{\circ} \mathrm{C}$ ) such as screen printing for fabricating their 


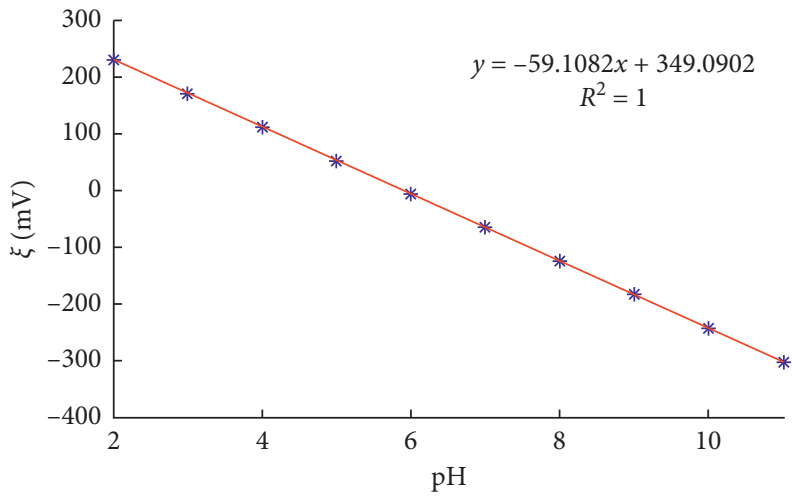

(a)

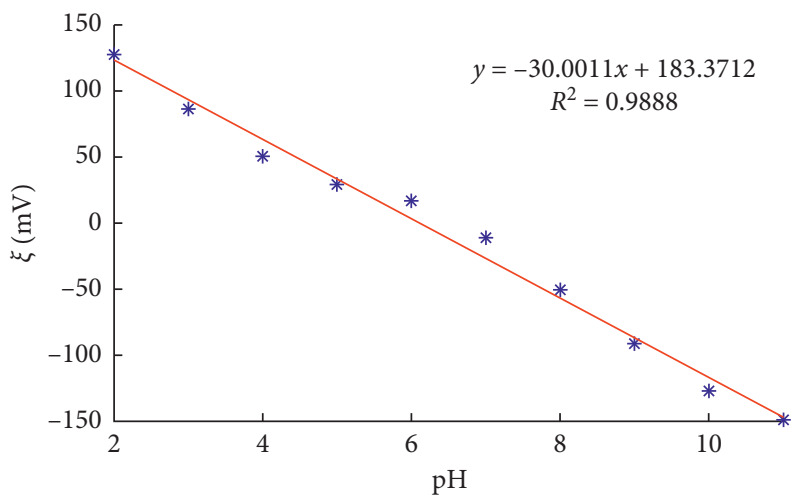

(c)

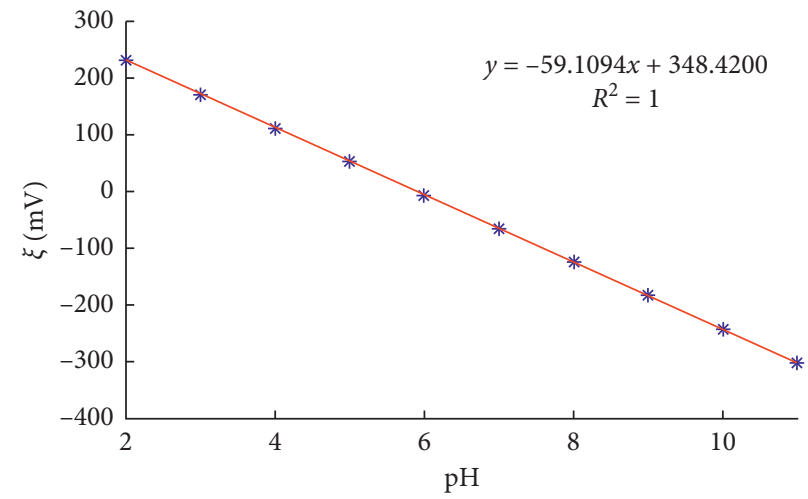

(b)

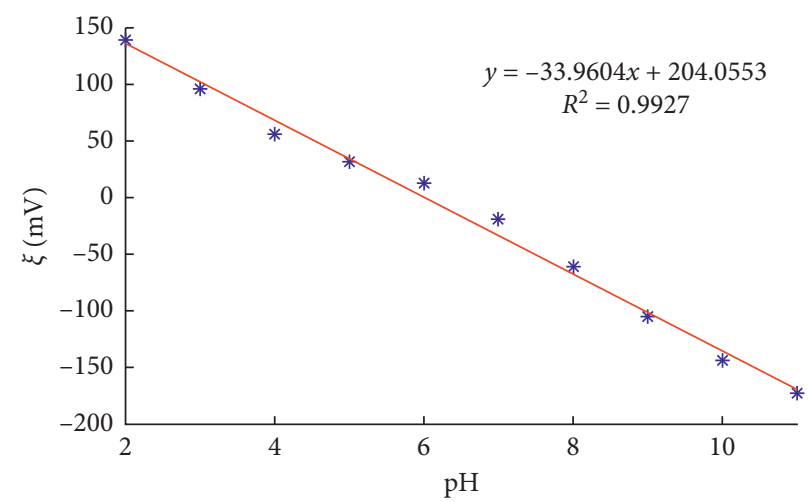

(d)

Figure 7: Total electrode potential $\xi$ against $\mathrm{pH}$ for (a) $\mathrm{RuO}_{2}$ (rutile: unhydrated), $N_{s}: 12.642, \varepsilon_{s}: 55.23$, (b) $\mathrm{RuO}_{2}$ (rutile: hydrated), $N_{s}$ : 17.642, $\varepsilon_{s}: 55.23$, (c) $\mathrm{TiO}_{2}$ (rutile), $N_{s}: 2.7, \varepsilon_{s}: 80$, and (d) $\mathrm{TiO}_{2}, N_{s}: 5$ (rutile), $\varepsilon_{s}: 80$. The electrolyte is $\mathrm{KCl}$ for all cases.

metal oxide electrodes observed a sub-Nernstian $\mathrm{pH}$ sensitivity for nonideal $\mathrm{MO}_{X}$ electrodes.

The observation of an invariant $\mathrm{pH}$ sensitivity value with regard to electrolyte ionic strength at a low capacitance value for the three different metal oxides in a lowtemperature annealing phase indicates that this phase allows for low $C_{1}$ capacitance buildup. This in turn allows for a high Nernstian sensitivity to be observed in these phases which is in line with the experimental results $[9,64]$. The fact that $\mathrm{Al}_{2} \mathrm{O}_{3}$ manifests a similar behaviour to that of the other two metal oxides in terms of sensitivity performance in the low-temperature-annealed phase seems significant as this could position $\mathrm{Al}_{2} \mathrm{O}_{3}$ as another alternative material for metal oxide $\mathrm{pH}$ sensors.

The sub-Nernstian $\mathrm{pH}$ sensitivities seen in high-temperature-annealed phases, with the exception of $\mathrm{RuO}_{2}$, indicate that surface site density $\left(N_{s}\right)$ has a significant impact on the sensitivity of the $\mathrm{pH}$ sensor. It could also be observed that, among the high-temperature-annealed metal oxides excluding $\mathrm{RuO}_{2}$, a greater $N_{s}$ results in only a marginal improvement in $\mathrm{pH}$ sensitivity but a significant increase in $C_{1}$ capacitance buildup. This is evident in the observation where an increase in $N_{s}$, for the $\mathrm{Ta}_{2} \mathrm{O}_{5}$ system, from 4 to 6 sites $/ \mathrm{nm}^{2}$ results in an increase in the $\mathrm{pH}$ sensitivity of $5.5 \%$ from 34.6 to $36.5 \mathrm{mV} / \mathrm{pH}$ but an increase in the $C_{1}$ capacitance of $42 \%$ from 298.5 to $423.9 \mu \mathrm{F} / \mathrm{cm}^{2}$. This means that not only does $N_{s}$ play a role in the sensitivity of the $\mathrm{pH}$ sensor but also $C_{1}$ capacitance buildup. The exact role of $N_{s}$ affecting $C_{1}$ capacitance buildup and subsequently $\mathrm{pH}$ sensitivity merits further investigation.

5.3. Potentiometric Analysis Based on the Proposed Engineering Model. Figures 7-9 show the total electrode potential $(\xi)$ plotted against $\mathrm{pH}$ across different phases and different metal oxides based on derived $C_{1}$ capacitances from the electrolyte ionic strength invariant engineering model proposed in this work. The equation of the linear regression fit has been shown. The slope of the equation represents the sensitivity of the corresponding $\mathrm{MO}_{X}$ system.

The low-temperature-annealed metal oxide phases and $\mathrm{RuO}_{2}$ graphs of Figures 7(a), 7(b), and 9 show excellent agreement of the data points to the linear regression fit line as seen from the high $R^{2}$ value of 1 . On the contrary, the remaining high-temperature-annealed phases of Figures $7(\mathrm{c}), 7(\mathrm{~d})$, and 8 have marginally lower $R^{2}$ value ranging from 0.9784 to 0.9947 . This is especially prominent with numerical runs with lower $N_{s}$ values such as in Figures $8(\mathrm{~b})$ and $8(\mathrm{c})$. This deviation from linearity is more prominent at data points taken near the pHpzc of the respective metal oxides, which are 3.9 for $\mathrm{Ta}_{2} \mathrm{O}_{5}, 5.3-5.7$ for $\mathrm{TiO}_{2}$, and 8.8 for $\mathrm{Al}_{2} \mathrm{O}_{3}$. The pHpzc point is an important parameter that determines the affinity of the electrode surface to the ions in the electrolyte [67]. 


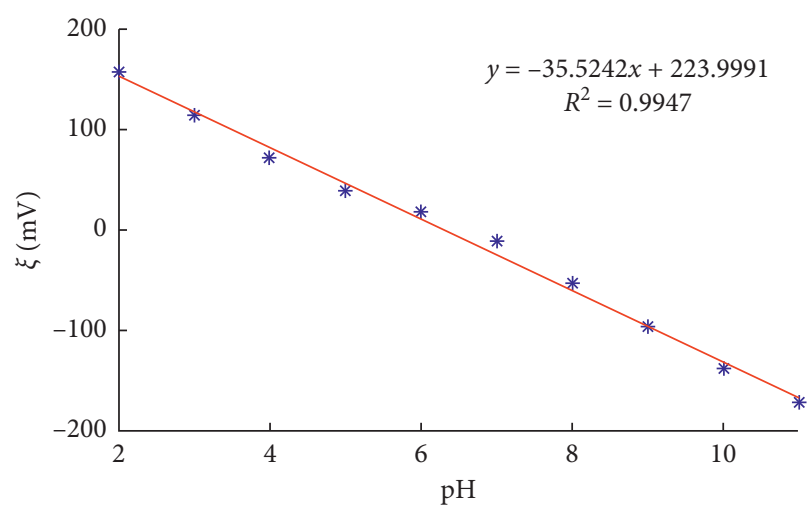

(a)

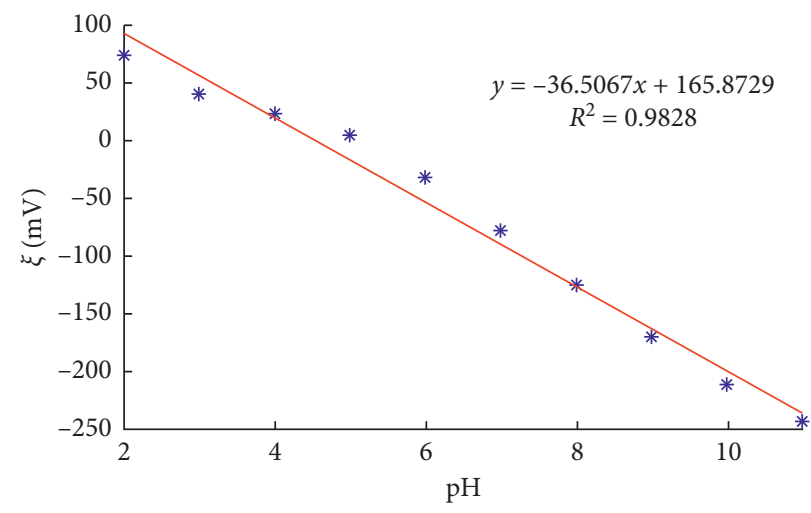

(c)

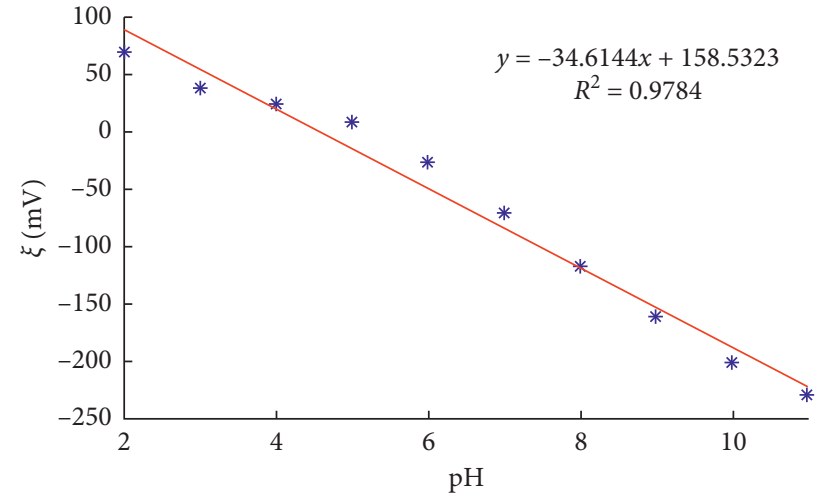

(b)

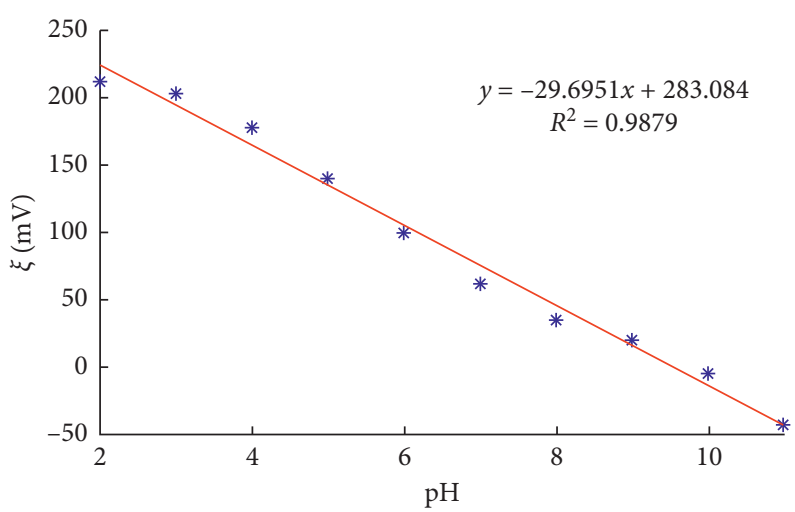

(d)

Figure 8: Total electrode potential $\xi$ against $\mathrm{pH}$ for (a) $\mathrm{TiO}_{2}, N_{s}: 7$ (anatase), $\varepsilon_{s}: 35$, (b) $\mathrm{Ta}_{2} \mathrm{O}_{5}, N_{s}: 4, \varepsilon_{s}: 50,(\mathrm{c}) \mathrm{Ta}_{2} \mathrm{O}_{5}, N_{s}: 6, \varepsilon_{s}: 50$, and (d) $\mathrm{Al}_{2} \mathrm{O}_{3}, N_{s}: 1.3, \varepsilon_{s}: 10.43$. The electrolyte is $\mathrm{KCl}$ for all cases.

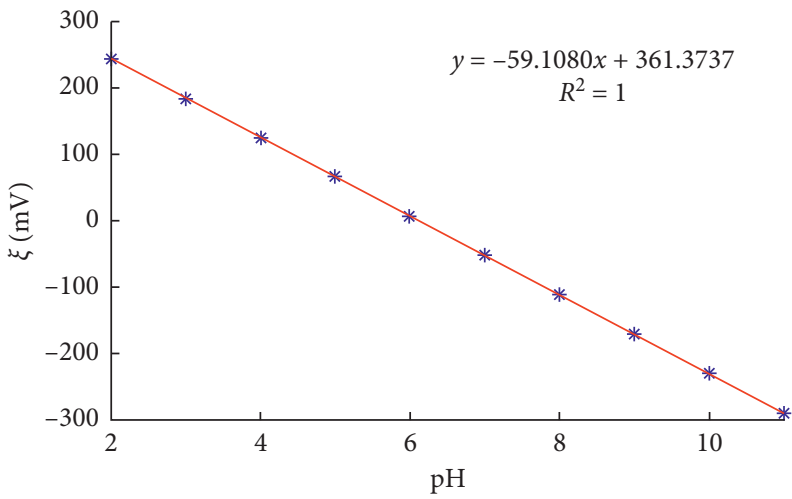

(a)

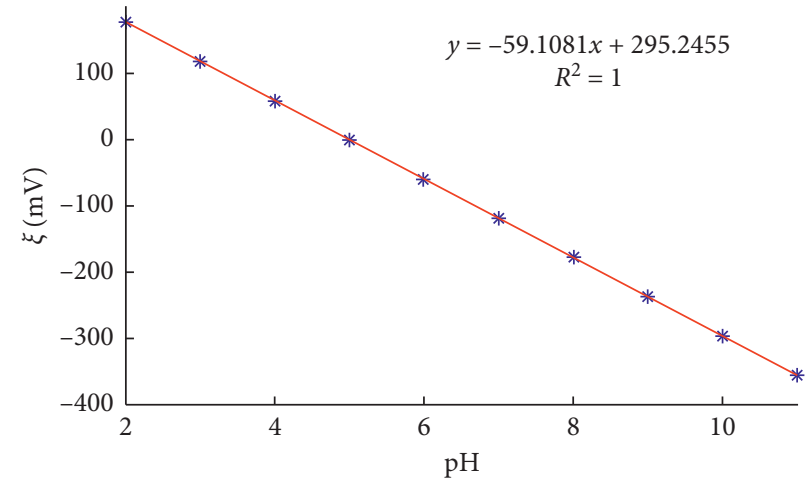

(b)

Figure 9: Continued. 


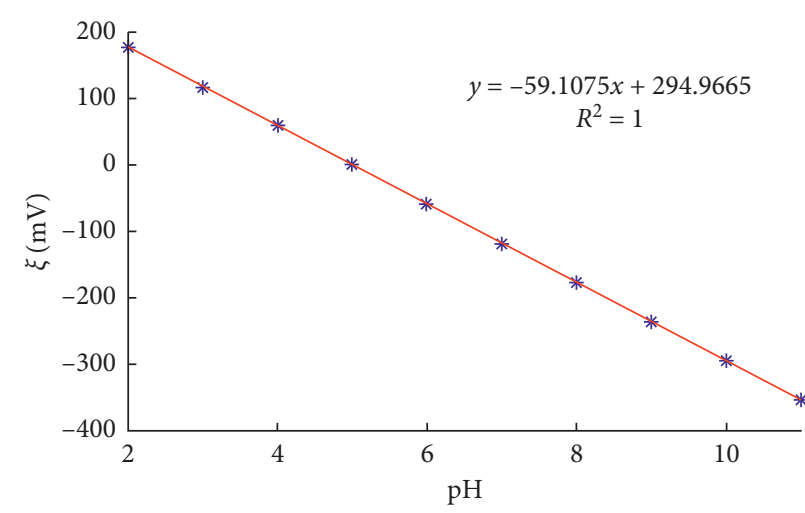

(c)

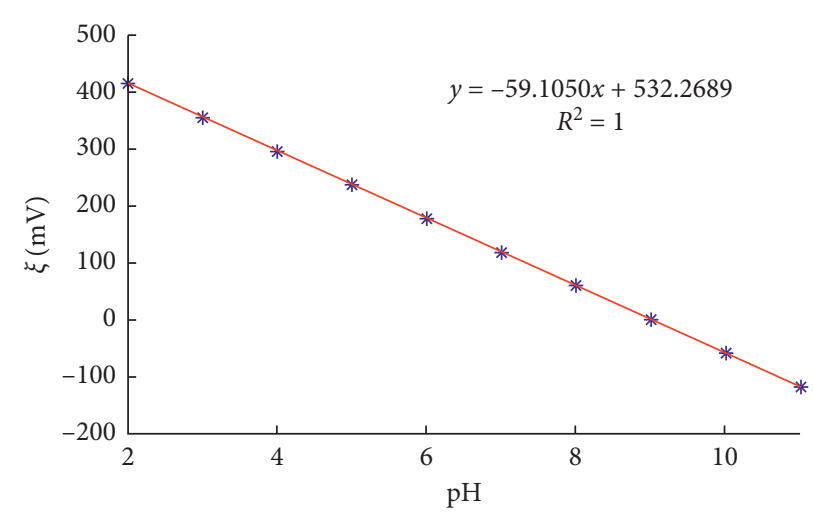

(d)

FIgure 9: Total electrode potential $\xi$ against $\mathrm{pH}$ for (a) $\mathrm{TiO}_{2}, \mathrm{~N}_{s}: 12.05, \varepsilon_{s}: 35$, (b) $\mathrm{Ta}_{2} \mathrm{O}_{5}, N_{s}: 10, \varepsilon_{s}: 25$, (c) $\mathrm{Ta}_{2} \mathrm{O}_{5}, N_{s}: 12, \varepsilon_{s}: 25$, and (d) $\mathrm{Al}_{2} \mathrm{O}_{3}$, $N_{s}: 12.04, \varepsilon_{s}: 10.43$. The electrolyte is $\mathrm{KCl}$ for all cases.

At the pHpzc point, the electrode surface has a net charge of zero. In low $\mathrm{pH}$ ranges (acidic regime) where solution $\mathrm{pH}$ is lower than the $\mathrm{pHpzc}$, the electrode surface is positively charged. On the contrary, in higher $\mathrm{pH}$ ranges (basic regime), the electrode surface is negatively charged [68]. The acidic and basic regimes, away from the pHpzc point, are observed to have a more linear trend with notable exception for $\mathrm{Al}_{2} \mathrm{O}_{3}$ where the acidic regime tends to show a deviation from linearity.

These results show that a greater site density, apart from improving the magnitude of sensitivity, also ensures that the sensitivity is consistent across the $\mathrm{pH}$ range 2 to 11 . On the contrary, a lower site density results in poorer sensitivity to occur in the immediate neighbourhood of the pHpzc than the acidic and alkaline regimes. Therefore, when using these metal oxides, it is imperative to find the pHpzc of the metal oxide material and determine if this lies within the $\mathrm{pH}$ range of interest for the end-use context of this $\mathrm{pH}$ sensor.

\section{Conclusion and Future Work}

One of the major impediments in applying the TLM in the context of estimating the sensitivity of $\mathrm{pH}$ sensors is the independent determination of the inner Helmholtz layer capacitance $C_{1}$. In this work, we have proposed a new methodology to theoretically estimate the sensitivity of $\mathrm{pH}$ sensors which effectively addresses this problem by identifying an electrolyte concentration invariant point in the sensitivity response to $C_{1}$ variation trends. The corresponding value of $C_{1}$ and $\mathrm{pH}$ sensitivity at this invariance point can be considered as characteristics of $\mathrm{MO}_{X}$. The percentage difference between the calculated and experimentally observed values was below $6 \%$ across three $\mathrm{MO}_{X}$ $\left(\mathrm{RuO}_{2}, \mathrm{TiO}_{2}\right.$, and $\left.\mathrm{Ta}_{2} \mathrm{O}_{5}\right)$ and annealing methods where such experimental sensitivities were available. As observed for $\mathrm{TiO}_{2}$ and $\mathrm{Ta}_{2} \mathrm{O}_{5}$, the percentage difference between the values was lower (less than 2\%) for low-temperature annealing methods as compared to high-temperature annealing methods. The consistent and close agreement of $\mathrm{pH}$ sensitivity thus determined, with experimentally observed values, across different $\mathrm{MO}_{X}$ validates the methodology and its utility.

The proposed engineering model and the methodology distinguish the performance of different metal oxide phases by choosing appropriate surface hydroxyl site densities and dielectric constants. It is therefore possible to theoretically estimate the performance of metal oxide electrodes fabricated through different methods, namely, high-temperature and low-temperature annealing. Low-temperature annealing methods provide higher site densities, resulting in higher $\mathrm{pH}$ sensitivity values, while high-temperature annealing methods provide lower site densities, resulting in poorer $\mathrm{pH}$ sensitivity. This was evident from the fact that the sensitivities of nonplatinum group $\mathrm{MO}_{X}$ such as $\mathrm{TiO}_{2}$ and $\mathrm{Ta}_{2} \mathrm{O}_{5}$ fabricated through low-temperature annealing methods were predicted to be close to Nernstian sensitivities of 59.1050 and $59.1081 \mathrm{mV} / \mathrm{pH}$. With the exception of $\mathrm{RuO}_{2}$, an "active" platinum group $\mathrm{MO}_{X}$ (sensitivity of $59.1082 \mathrm{mV} /$ $\mathrm{pH})$ and the other $\mathrm{MO}_{X}$ analysed $\left(\mathrm{TiO}_{2}\right.$ and $\left.\mathrm{Ta}_{2} \mathrm{O}_{5}\right)$, fabricated through high-temperature annealing methods, were predicted to have sub-Nernstian sensitivities of 30.0011 and 34.6144 , respectively. These conclusions arrived by applying the model across three different metal oxides, namely, $\mathrm{RuO}_{2}$, $\mathrm{TiO}_{2}$, and $\mathrm{Ta}_{2} \mathrm{O}_{5}$, are consistent with experimental observations found in the literature.

The model was also applied to a relatively less investigated material $\mathrm{Al}_{2} \mathrm{O}_{3}$, in the context of potentiometric $\mathrm{pH}$ sensors. Low-temperature-annealed $\mathrm{Al}_{2} \mathrm{O}_{3}$ shows promise as a viable electrode material with a predicted Nernstian sensitivity of $59.105 \mathrm{mV} / \mathrm{pH}$, which can be validated experimentally in the future. This is potentially a significant result since $\mathrm{Al}_{2} \mathrm{O}_{3}$ is widely available and is considerably cheaper as compared to other platinum group $\mathrm{MO}_{X}$ traditionally used for fabrication sensor electrodes. On the contrary, high-temperature-annealed $\mathrm{Al}_{2} \mathrm{O}_{3}$, with a predicted sub-Nernstian sensitivity of $29.6951 \mathrm{mV} / \mathrm{pH}$, displays characteristics similar to other nonplatinum group $\mathrm{MO}_{X}$ such as $\mathrm{TiO}_{2}$ and $\mathrm{Ta}_{2} \mathrm{O}_{5}$.

The engineering model proposed helps in conducting focused experiments in this domain. Further investigation on the impact of site density by different fabrication methods 
would help provide a better estimate of the $\mathrm{pH}$ sensitivity of the electrode. This work can be further extended to investigate the sensitivity performance of mixed metal oxide mixtures. There can also be an investigation into the relationship between the surface site density and $C_{1}$ inner Helmholtz capacitance as these two parameters are observed to be the major factors that influence $\mathrm{pH}$ sensitivity.

\section{Data Availability}

The data used to support the findings of this study are available from the corresponding author upon request.

\section{Conflicts of Interest}

The authors declare that they have no conflicts of interest.

\section{Acknowledgments}

This work was supported by Sreemagal Computers (Grant no. SC/2020-21/Sensors/284060626574) from Sreemagal Science Foundation, Chennai, India.

\section{References}

[1] D. Nunes, "Metal oxide nanostructures for sensor applications," Semiconductor Science and Technology, vol. 34, no. 4, Article ID 043001, 2019.

[2] M. N. Nikola, E. M. Huesman, M. J. Van den Hof, and I. S. Andrzej, "Opportunities and challenges for process control in process intensification," Chemical Engineering and Processing: Process Intensification, vol. 52, no. 1-15, 2012.

[3] W. Lonsdale, M. Wajrak, and K. Alameh, "Manufacture and application of $\mathrm{RuO}_{2}$ solid-state metal-oxide $\mathrm{pH}$ sensor to common beverages," Talanta, vol. 180, pp. 277-281, 2018.

[4] E. Tanumihardja, W. Olthuis, and A. Van den Berg, "Ruthenium oxide nanorods as potentiometric $\mathrm{pH}$ sensor for organs-on-chip purposes," Sensors, vol. 18, no. 9, 2018.

[5] L. Santos, J. P. Neto, A. Crespo et al., " $\mathrm{WO}_{3}$ nanoparticlebased conformable $\mathrm{pH}$ sensor," ACS Applied Materials \& Interfaces, vol. 6, no. 15, pp. 12226-12234, 2014.

[6] L. Manjakkal, D. Szwagierczak, and R. Dahiya, "Metal oxides based electrochemical $\mathrm{pH}$ sensors: current progress and future perspectives," Progress in Materials Science, vol. 109, Article ID 100635, 2020.

[7] M. Chen, Y. Jin, X. Qu, Q. Jin, and J. Zhao, "Electrochemical impedance spectroscopy study of $\mathrm{Ta}_{2} \mathrm{O}_{5}$ based EIOS $\mathrm{pH}$ sensors in acid environment," Sensors and Actuators B: Chemical, vol. 192, pp. 399-405, 2014.

[8] C. Ravichandran, M. Noel, and P. N. Anantharaman, "The $\mathrm{pH}$-dependence of thermally-coated $\mathrm{Ti} / \mathrm{TiO}_{2}$ electrodes in the absence and presence of nitrobenzene," Journal of Applied Electrochemistry, vol. 26, no. 2, pp. 195-201, 1996.

[9] D.-H. Kwon, B.-W. Cho, C.-S. Kim, and B.-K. Sohn, "Effects of heat treatment on $\mathrm{Ta}_{2} \mathrm{O}_{5}$ sensing membrane for low drift and high sensitivity pH-ISFET," Sensors and Actuators B: Chemical, vol. 34, no. 1-3, pp. 441-445, 1996.

[10] L. Manjakkal, K. Cvejin, K. Jan, K. Zaraska, and D. Szwagierczak, "A low-cost $\mathrm{pH}$ sensor based on $\mathrm{RuO}_{2}$ resistor material," in Nano Hybrids (Volume 5), pp. 1-15, Scientific.Net, Zurich, Switzerland, 2013.

[11] Y.-H. Liao and J.-C. Chou, "Preparation and characteristics of ruthenium dioxide for $\mathrm{pH}$ array sensors with real-time measurement system," Sensors and Actuators B: Chemical, vol. 128, no. 2, pp. 603-612, 2008.

[12] L. Manjakkal, K. Zaraska, K. Cvejin, J. Kulawik, and D. Szwagierczak, "Potentiometric $\mathrm{RuO}_{2}-\mathrm{Ta}_{2} \mathrm{O}_{5} \mathrm{pH}$ sensors fabricated using thick film and LTCC technologies," Talanta, vol. 147, pp. 233-240, 2016.

[13] L. A. Pocrifka, C. Goncalves, P. Grossi, P. C. Colpa, and E. C. Pereira, "Development of $\mathrm{RuO}_{2}-\mathrm{TiO}_{2}(70-30) \mathrm{mol} \%$ for $\mathrm{pH}$ measurements," Sensors and Actuators B: Chemical, vol. 113, no. 2, pp. 1012-1016, 2006, Special Issue - In honour of Professor Karl Cammann.

[14] L. Manjakkal, K. Cvejin, J. Kulawik, K. Zaraska, D. Szwagierczak, and G. Stojanovic, "Sensing mechanism of $\mathrm{RuO}_{2}-\mathrm{SnO}_{2}$ thick film $\mathrm{pH}$ sensors studied by potentiometric method and electrochemical impedance spectroscopy," Journal of Electroanalytical Chemistry, vol. 759, pp. 82-90, 2015.

[15] A. Fog and R. P. Buck, "Electronic semiconducting oxides as pH sensors," Sensors and Actuators, vol. 5, no. 2, pp. 137-146, 1984.

[16] P. M. Biesheuvel, S. Porada, and J. E. Dykstra, The Difference between Faradaic and Non-Faradaic Electrode Processes, 2020.

[17] A. J. Bard and L. R. Faulkner, Electrochemical Methods: Fundamentals and Applications, Wiley, Hoboken, NJ, USA, 2nd edition, 2001.

[18] L. Manjakkal, K. Cvejin, B. Bajac, J. Kulawik, K. Zaraska, and D. Szwagierczak, "Microstructural, impedance spectroscopic and potentiometric analysis of $\mathrm{Ta}_{2} \mathrm{O}_{5}$ electrochemical thick film pH sensors," Electroanalysis, vol. 27, no. 3, pp. 770-781, 2015.

[19] M. K. Hatalis and D. W. Greve, "Large grain polycrystalline silicon by low-temperature annealing of low-pressure chemical vapor deposited amorphous silicon films," Journal of Applied Physics, vol. 63, no. 7, pp. 2260-2266, 1988.

[20] A. S. Bakri, M. Z. Sahdan, F. Adriyanto et al., "Effect of annealing temperature of titanium dioxide thin films on structural and electrical properties," AIP Conference Proceedings, vol. 1788, no. 1, Article ID 030030, 2017.

[21] S. Al-Hilli and M. Willander, "The $\mathrm{pH}$ response and sensing mechanism of n-type $\mathrm{ZnO} /$ electrolyte interfaces," Sensors, vol. 9, no. 9, pp. 7445-7480, 2009.

[22] P. Woias, L. Meixner, D. Amandi, and M. Schonberger, "Modelling the short-time response of ISFET sensors," Sensors and Actuators B: Chemical, vol. 24, no. 1-3, pp. 211-217, 1995.

[23] P. Kurzweil, "Metal oxides and ion-exchanging surfaces as $\mathrm{pH}$ sensors in liquids: state-of-the-art and outlook," Sensors, vol. 9, no. 6, pp. 4955-4985, 2009.

[24] S. Trasatti, "Physical electrochemistry of ceramic oxides," Electrochimica Acta, vol. 36, no. 2, pp. 225-241, 1991.

[25] D. A. Sverjensky and N. Sahai, "Theoretical prediction of single-site surface-protonation equilibrium constants for oxides and silicates in water," Geochimica et Cosmochimica Acta, vol. 60, no. 20, pp. 3773-3797, 1996.

[26] R. Krishnan, "Fundamentals of semiconductor electrochemistry and photoelectrochemistry," Encyclopedia of Electrochemistry, vol. 6, pp. 1-53, 2007.

[27] X. G. Zhang, Electrochemistry of Silicon and Its Oxide, Springer, Berlin, Germany, 2014.

[28] J. A. Davis, R. O. James, and J. O. Leckie, "Surface ionization and complexation at the oxide/water interface," Journal of Colloid and Interface Science, vol. 63, no. 3, pp. 480-499, 1978.

[29] S. Rashidi, H. Bafekr, M. S. Valipour, and J. A. Esfahani, “A review on the application, simulation, and experiment of the 
electrokinetic mixers," Chemical Engineering and Processing-Process Intensification, vol. 126, pp. 108-122, 2018.

[30] A. S. Dimitri, "Interpretation and prediction of triple-layer model capacitances and the structure of the oxide-electrolytewater interface," Geochimica et Cosmochimica Acta, vol. 65, no. 21, pp. 3643-3655, 2001.

[31] I. F. McConvey, K. Scott, J. M. Henderson, and A. N. Haines, "Electrochemical reaction with parallel reversible surface adsorption: interpretations of the kinetics of anodic oxidation of aniline and phenol to carbon dioxide," Chemical Engineering and Processing: Process Intensification, vol. 22, no. 4, pp. 231-235, 1987.

[32] Y. S. Hwang and J. J. Lenhart, "The dependence of hematite site-occupancy standard state triple-layer model parameters on inner-layer capacitance," Journal of Colloid and Interface Science, vol. 319, no. 1, pp. 206-213, 2008.

[33] G. E. Brown, V. E. Henrich, W. H. Casey et al., "Metal oxide surfaces and their interactions with aqueous solutions and microbial organisms," Chemical Reviews, vol. 99, no. 1, pp. 77-174, 1999, PMID: 11848981.

[34] S. Chalupczok, P. Kurzweil, H. Hartmann, and C. Schell, "The redox chemistry of ruthenium dioxide: a cyclic voltammetry study-review and revision," International Journal of Electrochemistry, vol. 2018, Article ID 1273768, 15 pages, 2018.

[35] D. Wang, J. Huang, F. Liu et al., "Rutile $\mathrm{RuO}_{2}$ dispersion on rutile and anatase $\mathrm{TiO}_{2}$ supports: the effects of support crystalline phase structure on the dispersion behaviors of the supported metal oxides," Catalysis Today, vol. 339, pp. 220-232, 2020.

[36] Z. Zhang, P. Fenter, N. C. Sturchio, M. J. Bedzyk, M. L. Machesky, and D. J. Wesolowski, "Structure of rutile $\mathrm{TiO}_{2}$ (110) in water and 1 molal $\mathrm{Rb}+$ at $\mathrm{pH} 12$ : inter-relationship among surface charge, interfacial hydration structure, and substrate structural displacements," Surface Science, vol. 601, no. 4, pp. 1129-1143, 2007.

[37] M. Elahifard, M. R. Sadrian, A. Mirzanejad, R. Behjatmanesh-Ardakani, and S. Ahmadvand, "Dispersion of defects in $\mathrm{TiO}_{2}$ semiconductor: oxygen vacancies in the bulk and surface of rutile and anatase," Catalysts, vol. 10, no. 4, p. 397, 2020.

[38] A. Fukumoto and K. Miwa, "Prediction of hexagonal $\mathrm{Ta}_{2} \mathrm{O}_{5}$ structure by first-principles calculations," Physical Review B, vol. 55, no. 17, pp. 11155-11160, 1997.

[39] P. Villars and K. Cenzual, $\theta-\mathrm{Al}_{2} \mathrm{O}_{3} \mathrm{M}-\theta$ Crystal Structure, Springer-Verlag, Berlin, Germany, 2016.

[40] Y. Lei, Y. Leng, P. Yang, G. Wan, and N. Huang, "Theoretical calculation and experimental study of influence of oxygen vacancy on the electronic structure and hemocompatibility of rutile $\mathrm{TiO}_{2}$," Science in China Series E: Technological Sciences, vol. 52, no. 9, pp. 2742-2748, 2009.

[41] E. Gongadze, S. Petersen, U. Beck, and U. Van Rienen, "Classical models of the interface between an electrode and an electrolyte," in Proceedings of the Excerpt from the Proceedings of the COMSOL Conference, pp. 14-16, Milano, Italy, 2009.

[42] D. A. McKeown, P. L. Hagans, P. L. Carette, A. E. Russell, K. E. Swider, and D. R. Rolison, "Structure of hydrous ruthenium oxides: implications for charge storage," The Journal of Physical Chemistry B, vol. 103, no. 23, pp. 4825-4832, 1999.

[43] Z.-J. Yang, Y.-D. Guo, L. Jin et al., "Electronic structure and optical properties of rutile $\mathrm{RuO}_{2}$ from first principles," Chinese Physics B, vol. 19, no. 7, Article ID 077102, 2010.

[44] C.-J. Chang, Y.-C. Chu, H.-Y. Yan, Y.-F. Liao, and H. M. Chen, "Revealing the structural transformation of rutile $\mathrm{RuO}_{2}$ via in situ X-ray absorption spectroscopy during the oxygen evolution reaction," Dalton Transactions, vol. 48, no. 21, pp. 7122-7129, 2019.

[45] P. F. Lang and B. C. Smith, "An equation to calculate internuclear distances of covalent, ionic and metallic lattices," Physical Chemistry Chemical Physics, vol. 17, no. 5, pp. 3355-3369, 2015.

[46] C. W. Hill, G. J. Derderian, and G. Sandhu, "Atomic layer deposition of hexagonal-phase $\mathrm{Ta}$ [sub 2] $\mathrm{O}$ [sub 5] using TaF [sub 5] and $\mathrm{H}$ [sub 2]O," Journal of The Electrochemical Society, vol. 152, no. 5, Article ID G386, 2005.

[47] I. D. Brown and D. Altermatt, "Bond-valence parameters obtained from a systematic analysis of the inorganic crystal structure database," Acta Crystallographica Section B Structural Science, vol. 41, no. 4, pp. 244-247, 1985.

[48] O. L. G. Alderman, C. J. Benmore, J. Neuefeind et al., "Amorphous tantala and its relationship with the molten state," Physical Review Materials, vol. 2, no. 4, Article ID 043602, 2018.

[49] R. De Palma, W. Laureyn, F. Frederix et al., "formation of dense self-assembled monolayers of ( $n$-Decyl) trichlorosilanes on $\mathrm{Ta} / \mathrm{Ta}_{2} \mathrm{O}_{5}$," Langmuir, vol. 23, no. 2, pp. 443-451, 2007, PMID: 17209592.

[50] L. A. Aleshina, V. P. Malinenko, A. D. Phouphanov, and N. M. Jakovleva, "The short-range order of anodic amorphous oxide films of Ta and Nb," Journal of Non-crystalline Solids, vol. 87 , no. 3, pp. 350-360, 1986.

[51] H. Tamura, A. Tanaka, K.-Y. Mita, and R. Furuichi, "Surface hydroxyl site densities on metal oxides as a measure for the ion-exchange capacity," Journal of Colloid and Interface Science, vol. 209, no. 1, pp. 225-231, 1999.

[52] R. O. James and G. A. Parks, "Characterization of aqueous colloids by their electrical double-layer and intrinsic surface chemical properties," in Surface and Colloid Science, pp. 119-216, Springer, Berlin, Germany, 1982.

[53] S. K. Kim, W.-D. Kim, K.-M. Kim, C. S. Hwang, and J. Jeong, "High dielectric constant $\mathrm{TiO}_{2}$ thin films on a Ru electrode grown at $250^{\circ} \mathrm{C}$ by atomic-layer deposition," Applied Physics Letters, vol. 85, no. 18, pp. 4112-4114, 2004.

[54] H. Zhang, B. Chen, J. F. Banfield, and G. A. Waychunas, "Atomic structure of nanometersized amorphous $\mathrm{TiO}_{2}$," Physical Review B, vol. 78, no. 12, Article ID 214106, 2008.

[55] M.-Y. Kuo, C.-L. Chen, C.-Y. Hua, H.-C. Yang, and P. Shen, "Density functional theory calculations of dense $\mathrm{TiO}_{2}$ polymorphs: implication for visible-light-responsive photocatalysts," The Journal of Physical Chemistry B, vol. 109, no. 18, pp. 8693-8700, 2005.

[56] H. Hohl and W. Stumm, "Interaction of $\mathrm{Pb}^{2+}$ with hydrous $\gamma-\mathrm{Al}_{2} \mathrm{O}_{3}$," Journal of Colloid and Interface Science, vol. 55, no. 2, pp. 281-288, 1976.

[57] J. A. Davis and D. B. Kent, Surface Complexation Modeling in Aqueous Geochemistry, Walter de Gruyter, Berlin, Germany, 1990pp. 177-260, chapter 5.

[58] P. Kurzweil, "Precious metal oxides for electrochemical energy converters: pseudocapacitance and $\mathrm{pH}$ dependence of redox processes," Journal of Power Sources, vol. 190, no. 1, pp. 189-200, 2009, Selected Papers presented at the 11th ULM ElectroChemical Days.

[59] D. González, J. Heras-Domingo, S. Pantaleone et al., "Water adsorption on $\mathrm{MO}_{2}(\mathrm{M}=\mathrm{Ti}, \mathrm{Ru}$, and Ir) surfaces. Importance of octahedral distortion and cooperative effects," ACS Omega, vol. 4, no. 2, pp. 2989-2999, 2019.

[60] L. Agosta, E. Brandt, and L. Alexander, "Diffusion and reaction pathways of water near fully hydrated $\mathrm{TiO}_{2}$ surfaces 
from ab initio molecular dynamics," The Journal of Chemical Physics, vol. 147, no. 2, Article ID 024704, 2017.

[61] B. Prasai, B. Cai, M. K. Underwood, J. P. Lewis, and D. A. Drabold, "Properties of amorphous and crystalline titanium dioxide from first principles," Journal of Materials Science, vol. 47, no. 21, pp. 7515-7521, 2012.

[62] D. E. Yates, S. Levine, and T. W. Healy, "Site-binding model of the electrical double layer at the oxide/water interface," Journal of the Chemical Society, Faraday Transactions, vol. 1, no. 70 , pp. $1807-1818,1974$

[63] M. A. A. Mohd Abdah, N. H. N. Azman, S. Kulandaivalu, and Y. Sulaiman, "Review of the use of transition-metal-oxide and conducting polymer-based fibres for highperformance supercapacitors," Materials \& Design, vol. 186, Article ID 108199, 2020.

[64] C. C. Jung and L. P. Liao, "Study of $\mathrm{TiO}_{2}$ thin films for ion sensitive field effect transistor application with RF sputtering deposition," Japanese Journal of Applied Physics, vol. 43, no. 1, pp. 61-65, 2004.

[65] J.-C. Chou and C.-W. Chen, "Fabrication and application of ruthenium-doped titanium dioxide films as electrode material for ion-sensitive extended-gate FETs," IEEE Sensors Journal, vol. 9, no. 3, pp. 277-284, 2009.

[66] T. P. Luxton, M. J. Eick, and K. G. Scheckel, "Characterization and dissolution properties of ruthenium oxides," Journal of Colloid and Interface Science, vol. 359, no. 1, pp. 30-39, 2011.

[67] M. Kosmulski, "The pH dependent surface charging and points of zero charge. VII. Update," Advances in Colloid and Interface Science, vol. 251, pp. 115-138, 2018.

[68] D. Ko lodynska, D. Fila, and Z. Hubicki, "Evaluation of possible use of the macroporous ion exchanger in the adsorption process of rare earth elements and heavy metal ions from spent batteries solutions," Chemical Engineering and Processing-Process Intensification, vol. 147, Article ID 107767, 2020. 